Xun $\mathrm{Xi}^{1}{ }^{1,2}$, Shangtong Yang ${ }^{1 *}$, Chun-Qing $\mathrm{Li}^{3}$, Meifeng $\mathrm{Cai}^{2}$, Xiaofei $\mathrm{Hu}^{4}$, Zoe K. Shipton ${ }^{1}$

${ }^{1}$ Department of Civil and Environmental Engineering, University of Strathclyde, Glasgow, G1 IXJ,

6 United Kingdom.

$7 \quad{ }^{2}$ School of Civil and Resource Engineering, University of Science and Technology Beijing, Beijing,

8 100083, China.

$9 \quad{ }^{3}$ School of Engineering, RMIT University, Melbourne, Vic 3001, Australia.

$10{ }^{4}$ State Key Laboratory of Structural Analysis for Industrial Equipment, Dalian University of 11 Technology, Dalian 116024, China.

\title{
12 ABSTRACT
}

13 Corrosion-induced concrete cracking is a significant problem affecting the durability of reinforced concrete structures. Considerable research has been carried out in addressing this problem but few have considered the cracking process of concrete as a mixed-mode fracture and the concrete as a multi-phase material. This paper develops a meso-scale mixed-mode fracture model for the cracking of concrete structures under non-uniform corrosion of reinforcement. Concrete is treated as a three-phase heterogeneous material, consisting of aggregates, mortar and interfaces. An example is worked out to demonstrate the application of the derived model and is then partially verified against previously published experimental results. In agreement with experimental results, the new model reproduces the observation that microcracks tend to form first at the interfaces before they connect to generate a discrete crack. Toughening mechanisms, e.g., microcrack shielding, crack deflection, aggregate bridging and crack overlap, have been captured in the model. Further, effects of aggregate randomness on the crack width development of concrete structures, differences between uniform and non-uniform corrosion and a comprehensive parametric study have been 27 investigated and presented.

28 Keywords: non-uniform corrosion, cohesive crack model, meso-scale, reinforced concrete structures, finite element method. 


\section{INTRODUCTION}

32

33

Reinforced concrete (RC) structures are widely used in civil engineering buildings, bridges, retaining walls, tunnels, piers, etc. However, in environments rich in chloride $\left(\mathrm{Cl}^{-}\right)$and carbon dioxide $\left(\mathrm{CO}_{2}\right)$, the reinforcement in concrete is prone to corrosion. Deterioration induced by corrosion of reinforcement is the greatest threat to the durability and service life of civil engineering structures. Worldwide, the maintenance and repair costs for corrosionaffected concrete infrastructure are estimated around $\$ 100$ billion per annum [1]. In the context of climate change, the corrosion problem for RC structures and infrastructures is likely to be exacerbated. Therefore, there is a well justified need for a thorough investigation of the corrosion-induced cracking process, not least bearing in mind that the determination of crack width is essential to the prediction of the serviceability of corrosion-affected RC structures and to decision making regarding the repairs for the structures [2].

To model the corrosion-induced cracking of concrete, analytical methods have been often employed to predict the time to surface cracking [3-6], crack patterns $[7,8]$ and crack width development $[2,9]$. Analytical models are rigorous in terms of mathematical formulation and can be easily applied in engineering applications. However, the boundary conditions that can be applied are limited and it is nearly impossible to predict the development of fractures through multi-phase materials, which retards the widespread application of the analytical method. Instead, researchers have resorted to numerical method for the problem of concrete cracking induced by reinforcement corrosion [10-18]. For example, Chen and Leung simulated concrete cover cracking by non-uniform corrosion of rebars of different locations within a concrete structure by inserting cohesive elements into predefined crack paths; different displacement boundary conditions were applied on two sides of geometries [19]. Xi and Yang modelled concrete cracking caused by non-uniform corrosion of multiple rebars 
and found that short spacing between rebars could cause delamination of the whole cover [20]. In most of these models, concrete is considered as a homogenous quasi-brittle material. The assumption of heterogeneity is flawed: concrete is a heterogeneous material at the mesoscale, consisting of aggregate particles, mortar and interfaces (usually known as ITZ). Šavija et al. [21] and Chen et al. [22] used a 2D heterogeneous lattice model to simulate the crack propagation and crack width development of concrete induced by linear decrease nonuniform corrosion model, and found when pitting corrosion occurs, significantly less total pressure is needed to crack the concrete cover compared to uniform corrosion. Du et al. [23] employed the damage plastic model to simulate failure of side-located and corner-located reinforcing bars under non-uniform corrosion by assuming the concrete as a three-phase material but only failure patterns and pressure are discussed.

Almost all numerical models have considered corrosion-induced cracking of concrete as a problem of tensile cracking $[19,21,24]$ (i.e., Mode I) or combined tensile cracking and compression damage $[12,13,23]$. The shear fracture (Mode II) of concrete has seldom been considered. Acoustic emission experiments on corrosion-induced concrete cracking have revealed that both Mode I and Mode II fracture mechanisms existed during the crack propagation, and the contribution of individual modes into the global fracture behaviour varies [25]. This is because, for the heterogeneous concrete, mixed-mode fracture will occur when cracks roughly propagating. In particular, under non-uniform corrosion as illustrated in Figure 1, both normal and shear stresses develop in around the corroded part of the reinforcement. It therefore becomes necessary to consider the corrosion-induced concrete cracking as a mixed-mode fracture process, rather than Mode I fracture only. Given very limited literature on mixed-mode fracture simulation of concrete caused by corrosion of reinforcement, we conducted a review on mixed-mode fracture simulation for other concrete 
structures. Gálvez et al. [26] investigated the influence of shear properties on mixed-mode fracture of concrete based on experimental results and macro-scale numerical analysis. They have found that cracking of concrete beams under bending tests is initiated under mixedmode but propagates under Mode I. Luciani et al. [27] discussed the constitutive model of cohesive element for mixed-mode fracture [28] and investigated the effects of Mode II fracture parameters on mixed-mode fracture of concrete at macro-scale; it has been found that Mode II parameters can change in a large range without noticeable change in results. Yang and $\mathrm{Xu}$ [29] built a heterogeneous cohesive model for four-point single-edge notched shear beam based on meso-scale random fields of fracture properties and found that simulations considering the shear fracture resistance showed a noticeable increase in the structural ductility or toughness over homogeneous models. The existing literature on mixed-mode fracture of concrete has not considered concrete as a multi-phase material in which case the toughening behaviour of aggregates and the weakening effect of interfaces cannot be simulated. Further, for corrosion-induced (non-uniform) cracking of concrete at meso-scale, the stress state is more complicated but so far there is no model which can fully address the mixed-mode fracture of heterogeneous concrete under (non-uniform) corrosion of reinforcement.

This paper attempts to develop a meso-scale mixed-mode fracture model for reinforced concrete structures subjected to non-uniform corrosion. Concrete is treated as a three-phase

102 heterogeneous material, consisting of aggregates, mortar and interfaces. In order to model arbitrary discrete cracking of concrete, cohesive crack elements are inserted into the mesh for all the phases, through an in-house script written in Python. A constitutive model for mixedmode fracture is introduced and discussed. An example is presented to demonstrate the application of the derived model and the model is partially verified through comparison with 
107 experimental results from the literature. We show that our model captures different 108 toughening mechanisms in concrete at the meso-scale. Repeatability of results and effects of

109 randomness are also discussed. Further, the contribution of shear in the fracture behaviour of

110 concrete under non-uniform corrosion expansion is examined. Finally, a parametric study is

111 presented, investigating the effects of some underlying parameters, e.g., shear fracture

112 energy, interface strength, cover thickness and uniform corrosion, on the crack pattern and 113 the development of crack width.

\section{NON-UNIFORM CORROSION MODEL}

116 When the reinforcement in concrete is corroded, the higher-volume corrosion products will

117 accumulate and push the surrounding concrete outwards which can cause cracking and 118 delamination of RC structures. As shown in Figure 1, $\phi$ is the diameter of the reinforcing bar 119 and $d_{0}$ is the thickness of the annular layer of concrete pores at the interface between the bar 120 and concrete, often referred to the "porous zone" [3] or "corrosion accommodation zone"

121 [30]. Usually $d_{0}$ is constant once concrete has hardened. In this study, $d_{0}$ is assumed $12.5 \mu \mathrm{m}$

122 [31]. Depending on the level of corrosion, the products of corrosion may occupy up to several 123 times more volume than the original steel [21]. It is assumed that no stress is produced and 124 exerted on the concrete until the "porous zone" around the reinforcement is fully filled by the 125 corrosion products. As the corrosion products proceed further in concrete, a band of corrosion 126 products forms, as shown in Figure 1. It has been found that the front of corrosion products 127 for the half of the rebar facing concrete cover is in a semi-elliptical shape, while corrosion of 128 the inward-facing half of rebar is negligibly small and can be neglected [32].

130 As illustrated in Figure 1, there may be three bands accommodating the corrosion products: the semi-elliptical band of corroded steel with maximum thickness $d_{c o-s t}$, the semi-elliptical 
rust band with maximum thickness $d_{m}$ (also referred to as corrosion expansion displacement

133 in this paper) and the circular band of porous concrete, $d_{0}$. The front of the corrosion is in a

134 semi-elliptical shape with the semi-major axis equal to $\phi / 2+d_{0}+d_{m}$ and the semi-minor

135 axis equal to $\phi / 2+d_{0}$.

136

137 By considering the original location of inner boundary of the concrete, i.e., $\phi / 2+d_{0}$, the

138 displacement boundary condition of the concrete structure $r(\theta)$ can be derived as follows,

$$
r(\theta)=\frac{\left(\phi+2 d_{0}+2 d_{m}\right)\left(\phi+2 d_{0}\right)}{\sqrt{\left(2 \phi+4 d_{0}\right)^{2}+16 d_{m}\left(\phi+2 d_{0}+d_{m}\right) \cos ^{2} \theta}}-\frac{\phi}{2}-d_{0}
$$

141 where $0 \leq \theta \leq \pi$.

143 Further, the relationship between maximum corrosion displacement $d_{m}$, as shown in Figure

144 1(b), and corrosion degree $\eta$ can be derived as follows:

$$
d_{m}=\frac{\eta \rho_{s t} \phi}{\alpha_{\text {rust }}}\left(\frac{1}{\rho_{\text {rust }}}-\frac{\alpha_{\text {rust }}}{\rho_{\text {st }}}\right)-2 d_{0}
$$

$\rho_{\text {rust }}$ is the density of corrosion products, $\rho_{s t}$ is the density of steel bar and $\alpha_{\text {rust }}$ is the molecular weight of steel divided by the molecular weight of corrosion products. Details of

148 the derived non-uniform corrosion model can be found in the authors' previous studies [8, 20]

149 while it is not repeated herein. It should be mentioned that, the non-uniform corrosion model

150 is derived from accelerated corrosion experiments exposed to chloride-rich environment [32].

\section{CONCRETE CRACK MODEL}

\subsection{Meso-scale discrete crack model of concrete}


154 In this paper, concrete is modelled as a three-phase material (i.e., consisting of aggregates, mortar and ITZ). In our model the shape of aggregate particles is simplified to a randomly sized and oriented polygon with 3 to 7 sides. The aggregate size distribution can be

157 represented by a grading curve, which is usually expressed in terms of cumulative percentage

158 passing through a series of sieves with different opening sizes. A typical gradation of

159 aggregate size distribution is listed in Table 1 [33]. For simplicity, only coarse aggregates

160 larger than $2.4 \mathrm{~mm}$ are modelled in this study, while fine aggregates and cement are treated as

161 mortar phase. Coarse aggregates generally occupy $40 \%$ of the whole volume of concrete. The

162 basic process of generating the multi-phase structure meso-scale is to produce and place

163 different aggregate particles in a repeated and random manner in the target area until it

164 reaches $40 \%$ of the area of the grid. First, an aggregate is generated with $3-7$ sides and a random size in specified grading segments. Then the aggregate is placed in the target area with a random position. There is a minimum distance between aggregates and boundary. More aggregates are generated and placed one by one until the total fraction of aggregates in

168 the grading segments reaches the specified value. There is no overlapping of aggregates in

169 the generating process. The remaining area becomes the target area for next smaller grading segments and the procedures are repeated until the last aggregate of smallest size is generated and placed. The 3-phase structure is generated from a Python script that populates drawings in AutoCAD; the structure is then imported into ABAQUS FE software for analysis.

174 To model arbitrary cracking in concrete, cohesive elements are embedded at the interfaces 175 throughout the mesh. A very fine mesh is produced to ensure random crack paths. The insertion process of cohesive elements is shown in Figure 2. First, all individual nodes are

177 replaced by certain number of new nodes at the same location. The number of newly created 178 nodes depends on the number of elements connecting to the original node. Second, the newly 
179 created nodes at the interface between two triangle elements are identified and linked to form

180 a cohesive element. The cohesive elements are shown in red in Figure 2. The cohesive

181 elements are generated by an in-house Python script. Figure 3 shows the inserted cohesive

182 elements at the interfaces of aggregates and mortar, as well as the aggregates and the mortar

183 themselves. The developed model is capable of simulating crack propagation and opening

184 both at the interface and in the bulk mortar and aggregates, depending on their mechanical 185 properties.

186

\section{$187 \quad 3.2 \quad$ Mixed-mode fracture model}

188 The cohesive crack model was first proposed by Hillerborg et al in 1976 [34] to model

189 discrete cracks and energy dissipation in the fracture process zone (FPZ) of concrete.

190 Normally, the cohesive element is of zero thickness to simulate the cracking of concrete;

191 therefore, a traction-separation law is usually employed to constitutively control the cohesive

192 elements. The traction of cohesive elements is a function of the corresponding relative

193 displacements of the crack surface. In general, the traction-separation laws for mode I and

194 mode II fracture can be expressed respectively as follows:

$$
\begin{aligned}
& \sigma_{n}=f_{n}\left(\delta_{n}\right) \\
& \sigma_{t}=f_{s}\left(\delta_{s}\right)
\end{aligned}
$$

196 where $\sigma_{n}$ and $\sigma_{t}$ are the normal traction and tangential traction, respectively; $\delta_{n}$ and $\delta_{s}$ are

197 the crack opening displacement and crack sliding displacement; $f_{n}$ and $f_{s}$ are the non-linear

198 functions defining the relationships between traction and separation for mode I and mode II

199 fracture, respectively.

201 However, due to complex loading condition, material heterogeneity and aggregate

202 interlocking etc., in most cases, cracks propagate in concrete under mixed-mode condition 
rather than in the single mode. Before the damage initiation, the normal stress $\sigma_{n}$ and shear

204 stress $\sigma_{t}$ have a linear relationship with the crack opening displacement $\delta_{n}$ and crack sliding

205 displacement $\delta_{s}$, which can be expressed as follows:

206

$$
\begin{aligned}
& \sigma_{n}=K_{p}<\delta_{n}> \\
& \sigma_{s}=K_{p} \delta_{s}
\end{aligned}
$$

207 where $<>$ is the Macaulay bracket and the normal stress equals to zero for compression 208 condition. $K_{p}$ is the penalty stiffness of the cohesive element. The concept of penalty

209 stiffness evolves from the elastic stiffness which is obtained by dividing the elastic modulus

210 of the concrete by its thickness. Since cohesive interface is normally very thin or of zero

211 thickness, the elastic stiffness of the cohesive interface approaches infinitesimally large. This

212 makes sense as the interface should be stiff enough prior to the initiation of crack to hold the

213 two surfaces of the bulk concrete together, leading to the same performance as if of no

214 interface existed. Therefore, the cohesive stiffness becomes a "penalty" parameter $\left(K_{p}\right)$,

215 which controls how easily the cohesive interface deforms elastically. As such this stiffness is

216 large enough to provide the same or close response of intact concrete prior to cracking, but

217 not so large as to cause numerical problems $[24,35,36]$.

218

219 A quadratic stress damage criterion is employed to determine the beginning of damage. The damage initiation law is expressed as follows:

$$
\left(\frac{<\sigma_{n}>}{\sigma_{n}^{0}}\right)^{2}+\left(\frac{\sigma_{s}}{\sigma_{s}^{0}}\right)^{2}=1
$$

222 where $\sigma_{n}^{0}$ and $\sigma_{s}^{0}$ are the tensile and shear cohesive strength of concrete, respectively. 
224 By using the same value of penalty stiffness $K_{p}$, the damage criterion can also be expressed 225 as follows:

$$
\left(\frac{<\delta_{n}>}{\delta_{n}^{0}}\right)^{2}+\left(\frac{\delta_{s}}{\delta_{s}^{0}}\right)^{2}=1
$$

227 where $\delta_{n}^{0}$ and $\delta_{s}^{0}$ are the critical displacement for mode I and mode II fracture, respectively.

$228 \delta_{n}^{0}$ and $\delta_{s}^{0}$ can be calculated by dividing the corresponding cohesive strength to the penalty 229 stiffness $K_{p}$. If the tensile strength is the same as shear strength, the function becomes a 230 circle with radius $\delta_{n}^{0}$ or $\delta_{s}^{0}$.

232 After the stress state meets the damage initiation criterion, the normal and shear stress 233 decrease gradually while the responding displacement continues to increase. Such stiffness 234 degradation behaviour is known as strain softening. For mixed-mode fracture, the damage is 235 characterised by one scalar variable $D$ representing the overall damage of the crack. For 2D 236 plane problem, the total mixed-mode effective relative displacement $\delta_{m}$ is introduced as:

$$
\delta_{m}=\sqrt{<\delta_{n}>^{2}+\delta_{s}^{2}}
$$

238 For linear softening, the expression for the damage model is given as follows:

$$
D=\frac{\delta_{m, f}\left(\delta_{m, \text { max }}-\delta_{m, 0}\right)}{\delta_{m, \text { max }}\left(\delta_{m, f}-\delta_{m, 0}\right)}
$$

240 where $\delta_{m, \max }$ is the maximum effective relative displacement during the loading history. $\delta_{m, 0}$

241 is the critical effective relative displacement when the damage starts (i.e., $D=0$ ). $\delta_{m, f}$ is the 242 effective relative displacement when complete failure occurs (i.e., $D=1$ ). The B-K failure 243 criterion proposed by Benzeggagh and Kenane [37] is used to capture the mixed-mode 
244 facture for different composite and quasi-brittle materials [28]. According to the B-K failure 245 criterion, $\delta_{m, f}$ can be expressed as follows:

$$
\delta_{m, f}=\frac{2}{K_{p} \delta_{m, 0}}\left[G_{I}+\left(G_{I I}-G_{I}\right)\left(\frac{G_{s}}{G_{n}+G_{s}}\right)^{\eta}\right]
$$

247 where $G_{I}$ and $G_{I I}$ are the fracture energy of mode I and mode II, respectively. $G_{n}$ and $G_{s}$ are

248 the work done by the tractions and their conjugate relative displacements in the normal, shear directions, respectively. $\eta$ is a characteristic parameter of materials, which can be set as 2 for composite quasi-brittle materials [28].

The mixed-mode fracture energy $G_{C}$ can be expressed as follows:

$$
G_{C}=\left[G_{I}+\left(G_{I I}-G_{I}\right)\left(\frac{G_{s}}{G_{n}+G_{s}}\right)^{\eta}\right]
$$

255 Clearly, for mode I fracture, $G_{s}=0$ and the contribution of shear on fracture (i.e., $\left.G_{s} /\left(G_{n}+G_{s}\right)\right)$ is zero. For mode II fracture, $G_{n}=0$ and the contribution of shear on fracture (i.e., $\left.G_{s} /\left(G_{n}+G_{s}\right)\right)$ is 1 .

259 Once the damage variable $D$ is determined, the residual normal and shear stresses can be 260 obtained by:

$$
\begin{aligned}
& \sigma_{n}=(1-D) K_{p} \delta_{n} \\
& \sigma_{s}=(1-D) K_{p} \delta_{s}
\end{aligned}
$$

262 If the overall damage variable $D$ reaches 1 , the normal and shear stresses are zero and the 263 cohesive element completely fails. 
265 Figure 4(a) illustrates the response model for mixed-mode fracture. It can be seen that, before 266 damage initiation, the normal, shear and effective stresses increase linearly by a slope

267 equivalent to the penalty stiffness. When the effective displacement (i.e., Equation 7) reaches

268 the inner ellipse shown in the $\delta_{s}-\delta_{n}$ plane in Figure 4(a) with semi-major axis $\delta_{s}^{0}$ and

269 semi-minor axis $\delta_{n}^{0}$, the damage is initiated and the stresses begin to decrease. For mixed-

270 mode fractures the fracture energy varies depending on the relative contributions of Mode I

271 and Mode II. Figure 4(b) shows a special case for mixed-mode fracture when the shear and

272 tensile strengths are same and fracture energies for mode I and mode II are the same. In this

273 case, the damage initiation ellipse becomes a circle with the radius equal to the strength.

274 Moreover, the mixed-mode fracture energy is equal to that of single mode fracture and the

275 effective relative displacement to complete failure will not change with the mixed-mode 276 ratio.

\section{WORKED EXAMPLE}

279 We demonstrate the application of the developed numerical method and techniques in solving non-uniform corrosion induced concrete cracking through a worked example. The values for all parameters are shown in Table 2, together with their sources. As in previous studies [26, $38,39]$, the shear fracture properties are hard to identify due to the lack of experimental data. Some researchers assume the shear properties are the same as the normal ones (i.e., $\sigma_{n}^{0}=\sigma_{s}^{0}$ and $\left.G_{I}=G_{I I}\right)[38,40,41]$. Some researchers postulated that shear properties have little effect on corrosion induced concrete cracking and only mode I fracture is considered in their model $[12,19,42]$. However, for a heterogeneous model with rough fracture surfaces, it is necessary to consider the effect of shear properties on concrete cracking. Experimental results on concrete samples indicated that the shear strength is greater than or equal to the tensile 
strength and the fracture energy for mode II is greater than that of mode I [26, 27]. Thus, in our model the shear strength is assumed the same as the tensile strength and the fracture energy for model II is twice that for mode I. Another important aspect for meso-scale fracture modelling of concrete is the fracture properties of ITZ. Experimental results indicated that the 293 tensile strength of ITZ is about $1 / 16^{\text {th }}$ to $3 / 4$ of the strength of the mortar matrix [42-46].

294 Accordingly the tensile strength of ITZ is set to half the tensile strength of the mortar matrix in this example. The average ratio of fracture energy $G_{I}$ to tensile strength (i.e., average

296 failure displacement) is about $0.013 \mathrm{~mm}$ in the experimental results from Rao and Prasad 297 [44]. We therefore assume in our case study that the value of facture energy $G_{I}$ for ITZ is 2980.013 times the tensile strength value of ITZ. The shear strength of ITZ is assumed the same as tensile strength of ITZ and the fracture energy for mode II is twice that of mode II. The mechanical properties of aggregates are normally considerably stronger than mortar and the ITZ; thus it is very rare to have a crack breaking through an aggregate. In this paper, fracture properties are only assigned in the ITZ and mortar, to reduce computational cost.

Figure 5 shows the typical mesh of the meso-scale RC cover structure with a middle rebar. The size of the RC structure is set $150 \times 150 \mathrm{~mm}$ and the thickness of concrete cover is $40 \mathrm{~mm}$. The average size of elements in the mesh is about $1.6 \mathrm{~mm}$, which is fine enough to simulate arbitrary cracks while keeping computational time reasonable. The non-uniform corrosion model developed in Section 2 is used to define the displacement boundary condition at the interface between the corroded rebar and the concrete.

311 Figure 6 shows the crack propagation process induced by non-uniform corrosion of 312 reinforcement. Cohesive elements with damage variable $D$ equal to 1 (i.e. complete failure) 313 are plotted in red. In order to more clearly illustrate the crack geometries and opening, the 
314 size of elements deformation is exaggerated by 10. It can be found that a few micro cracks

315 are first initiated at the aggregate-mortar interfaces near the upper surface of the concrete

316 cover. As corrosion continues, the micro cracks are then connected to form a dominant crack

317 propagating from the concrete surface to the rebar. The phenomenon of the crack propagating

318 from concrete surface towards the reinforcement is in good agreement with experiments [47].

319 As corrosion continues, two further cracks appear on the lateral margins of the corroded rebar,

320 as shown in Figure 6. Unlike macro-scale fracture modelling which normally considers

321 concrete as a homogeneous material, the meso-scale model can simulate the micro cracks

322 which always form first at the ITZ before they are connected to become a macro-scale

323 discrete crack. This is because the strength and fracture energy of ITZ cohesive elements are

324 significantly lower than those of mortar. Figure 7 illustrates the microcrack shielding, crack

325 deflection and aggregate bridging phenomena that have previously been very challenging to

326 simulate [20]. There are many microcracks appearing near the area of stress concentration

327 where the corrosion has developed furthest. Some of the microcracks will propagate, connect

328 and form a through-going crack. Crack deflection occurs when the potential crack path of

329 least resistance is around an aggregate or a weak interface. Aggregate bridging occurs when

330 the crack propagates along two sides of an aggregate and advances beyond the aggregate. As

331 such, the developed meso-scale fracture model is advantageous compared with most existing

332 concrete fracture models $[19,29]$ in terms of capturing toughening mechanisms and crack

333 propagation.

335 As introduced in the constitutive model for mixed-mode fracture and mechanical parameters

336 in this example, the shear strength is the same as tensile strength, and fracture energy for

337 mode II is greater than that for mode I. Thus, the effective displacement to damage initiation

338 for mixed-mode fracture is equal to that for the single mode I and mode II fracture. The 
339 higher the component of shear in a mixed-mode fracture, the larger the fracture energy is.

340 Figure 8 illustrates the relative contribution of shear fracture energy for the different cracked

341 elements which form the discrete cracks. In these models, the contribution of shear on the

342 fractures varies from about 0 to 0.9 during crack propagation ( 0 means Mode I fracture while

3431.0 means Mode II fracture). Most values for the contributions of shear are less than 0.5,

344 which indicates that the crack propagation is mixed-mode but mode I is dominant. It is 345 interesting to note that the higher contributions of shear occur where cracks have deflected 346 round aggregates, which indicated that more energy is required for the cracks bypassing the 347 aggregates.

349 For the heterogeneous concrete model, the aggregates are randomly generated but following 350 the same volume fraction, grading, size, etc. The effect of meso-scale randomness on crack 351 pattern and crack width should be investigated. Figure 9 shows the corrosion induced crack 352 patterns induced under four typical random meso-scale models. It can be seen that, three 353 discrete cracks, i.e., one top crack and two side cracks, always form around the reinforcing 354 bar. The crack patterns are quite similar in the four models, however, different shapes, size 355 and location of aggregates lead to cracks with different morphologies. For example, the cracked elements at the upper discrete crack in model 2 are deformed with more tangential displacement because of the presence of the large aggregate particle. It is interesting to find 358 that crack overlap occurs when two approximately parallel cracks propagate from weak 359 interfaces and interact with a variable overlap distance.

361 By measuring the distance between the two nodes of the surface cohesive element, the crack width development on the concrete surface under the maximum corrosion displacement $d_{m}$ can be schematically illustrated. It should be noted that this distance obtained initially 
364 represents the displacement of the surface cohesive element (often referred to as 365 cohesive/fictitious crack width); after the complete failure of this element, the distance 366 measured represents the true surface crack width. Figure 10 illustrates the crack width

367 development with maximum corrosion displacement $d_{m}$. It can be found that the crack width

368 initiates when $d_{m}$ increases to about $0.015 \mathrm{~mm}$ followed by a roughly linear increase of 369 crack width. The surface crack initiation occurs in a similar location above the corroded rebar 370 irrespective of meso-scale randomness, but the final crack width depends on the random 371 arrangement of the aggregate particles. This is reasonable because the aggregate distribution 372 will affect the mixed-mode fracture energy and the crack morphology has effect on crack 373 width. For example model 2 has the smallest crack width in Figure 9 because the contribution 374 of shear on the upper crack is greater. In general, the meso-scale fracture model in this study has a good repeatability.

\section{VERIFICATION}

378 To verify the proposed numerical method, the results are compared with experimental results

379 from Andrade et al [48]. According to the literature, most experimental test data are based on uniform corrosion of reinforcement generated by electric current method for producing accelerated corrosion. It would be ideal to compare directly the results between the developed model and experiments under non-uniform corrosion; however, the data on non-uniform corrosion is rather scarce. Additionally, almost all the experiments use an electric current to generate corrosion which, while producing results quickly, only produces generally uniform corrosion. In this paper, a uniform corrosion case is conducted by the derived model and the results are compared with those in [48] for partial verification. The values for basic parameters are presented in Table 3. It should be noted that the thickness of the "porous zone" between concrete and rebar is considered as $12.5 \mu \mathrm{m}$ in the numerical simulation. The 
experimental results of crack width were expressed as a function of the radius loss of rebar.

390 For the sake of comparison with the numerical results, the uniform corrosion displacement is

391 transformed to radius loss of rebar. The relationship between uniform corrosion expansion

392 displacement $d_{m, u}$ and radius loss of rebar $\Delta R$ can be expressed as follows:

$$
d_{m, u}=\left(\frac{\rho_{s t}}{\rho_{\text {rust }} \times \alpha_{\text {rust }}}-1\right) \times \Delta R-d_{0}
$$

The comparisons of the crack width from the developed numerical model and the experimental data of Andrade et al [48] are illustrated in Figure 11. The progress of the

397 simulated crack width is in reasonably good agreement with the experimental results. It 398 should be mentioned that the crack width from the experiments was measured by strain gauges; how the measured strains were transformed by Andrade et al [48] to crack width was not quite clear. However, the crack width from the numerical model was obtained by calculating the displacement of the surface cohesive element. The different method used for attaining the crack width might cause some minor difference in the results between the experiment and the numerical model. Moreover, it has been found that the crack width from the numerical model is slightly larger than that from the experiment. It is perhaps caused by the $2 \mathrm{D}$ plain strain assumption in the model since constraint effect in the third dimension is ignored and more complicated toughening mechanism exists in the real case.

407

\section{PARAMETRIC STUDY AND DISCUSSION}

409 As demonstrated in Figure 8, the Mode II fracture energy has a varying contribution to the

410 mixed-mode fracture. The effect of mode II fracture energy on concrete cracking induced by 411 non-uniform corrosion is investigated. Figure 12 shows the crack patterns of concrete cover 
412 under different shear fracture energy scenarios. The same fracture energy for mode I fracture

413 is used in the simulations. It can be seen that crack patterns are similar when the mode II

414 fracture energy varies from 2 times mode I fracture energy to 20 times (Figure 12 b,c,d).

415 However, the crack patterns have significant changes when the mode II fracture energy is the

416 same or 100 times of the mode I fracture energy (Figure 12 a and e). For $G_{I I}=G_{I}$, the

417 cracked elements in the three main cracks have larger tangential (i.e., shear) displacement

418 than in the other cases, and the discrete crack path tends to form along ITZs. In such a failure,

419 mode II shear mechanism plays an important role. For a relatively large value, i.e.,

$420 G_{I I}=100 G_{I}$, the failed elements (in red) in the discrete cracks are all in mode I fracture;

421 some elements with larger tangential displacement (in yellow box) are damaged but not completely failed because of the large mode II fracture energy. The greater the contribution of shear on a mixed-mode fracture, the more energy is required to form a discrete crack and the shear displacement becomes ductile after damage initiation. Figure 13 illustrates the crack width development under different fracture energies for mode II fracture. It can be found that the smaller the mode II fracture energy, the faster the crack width increases. The drop lines show complete failure of the first cracked cohesive element at surface of concrete. For mixed-mode fracture, the surface cracking time and complete failure displacement of cohesive element vary with the fracture energy of Mode I and Mode II and their contributions on facture. It can be seen in Figure 13, the larger the $G_{I I}$ is, the later the complete failure occurs (i.e., surface cracking). However, the value of $G_{I I}$ in the range of 2-20 times of $G_{I}$ has little effect on the crack width development. Therefore, for mixed-mode fracture of concrete, the mode II fracture energy has little influence on crack width development when it

434 is a relatively reasonable larger value than mode I fracture energy; but the shear fracture 435 parameters should not be ignored or regarded as the same as mode I fracture energy, 436 especially for meso-scale fracture modelling of concrete. 
438 The effects of strength of ITZ on concrete cover cracking are investigated using different ratios of tensile and shear strengths of ITZ to these of mortar. The ratios of mode I fracture energy to tensile strength and mode II fracture energy to shear strength are kept constant.

441 Figure 14 shows the crack patterns affected by the strength of ITZ. It can be seen that, the 442 lower the strength of ITZ, the more cracks form along the ITZs. When the strength of ITZ is 443 $1 / 8^{\text {th }}$ of the mortar, there are more intermittent discrete cracks appearing at the weak zones of ITZ than in the simulations where the ITZ are stronger. Figure 15 illustrates the crack width development under different values of ITZ strength. It can be found that, the lower the ITZ strength, the larger the crack width. For example, when $d_{m}$ reaches $0.2 \mathrm{~mm}$ (corrosion degree of steel bar is $0.64 \%$ ), the crack width for strength of ITZ $1 / 8^{\text {th }}$ that of mortar is 0.3 mm which is $30 \%$ larger than the crack width for strength of ITZ $3 / 4$ of that of mortar. Therefore, it is important to improve the strength of ITZ for durability of RC structures.

Figure 16 shows the crack patterns of concrete cover affected by cover thickness. It can be seen that, for thinner cover, the side cracks have a tendency to propagate towards the surface and thus the volume of cover that may spall from the concrete surface smaller. The concrete thickness has little effect on the position of the upper crack. Figure 17 illustrates the crack width development for different cover thicknesses. As expected, the thicker the cover is, the later the cohesive crack width increases. It is interesting to find that once the surface is cracked, the crack width becomes larger when the cover thickness is larger. It is probably because the corresponding strain at the surface for larger cover thickness induced by nonuniform corrosion products expansion is larger. However, it should be mentioned that, a

460 thicker cover will delay the time to corrosion initiation which is not considered in the model. 
461 Thus, a thicker cover should still delay the time to surface cracking; however, after the surface of concrete cover is cracked, the crack width will increase faster for thicker cover.

464 Most previous studies about corrosion-induced concrete cracking have been based on 465 uniform corrosion. It is necessary to compare the difference of concrete cracking between 466 uniform corrosion and non-uniform corrosion. Figure 18 shows the uniform corrosion 467 induced crack patterns for cover thickness $20 \mathrm{~mm}$ and $40 \mathrm{~mm}$. For uniform corrosion, two discrete cracks form vertically and the top crack has a larger crack width, which is consistent with experimental results from [48]. Figure 19 illustrates the crack width affected by corrosion model and cover thickness. It can be found that, the crack widths for non-uniform corrosion begin increasing earlier than those for uniform corrosion. This is mainly because for uniform corrosion, more corrosion products are required to fill in the "porous zone" between concrete and reinforcement. Moreover, the crack width induced by non-uniform corrosion is larger than that by uniform corrosion. The thicker the cover is, the larger the difference of crack width between non-uniform and uniform corrosion. Therefore, the models based on uniform corrosion of reinforcement overestimate the time to surface cracking and crack width, especially for thicker cover cases.

\section{CONCLUSIONS}

480 In this paper, a meso-scale mixed-mode model has been developed to simulate discrete crack 481 propagation in concrete and to predict the crack width induced by corrosion of reinforcement.

482 A non-uniform corrosion model was first described based on previous experimental results. A three phase (i.e., aggregates, mortar and interfaces) heterogeneous concrete model was considered and a mixed-mode fracture model was formulated. It has been found that microcracks tend to form first at the ITZ before they connect to generate a discrete crack. 
486 Some toughening mechanisms were also captured, e.g., microcrack shielding, crack

487 deflection, aggregate bridging and crack overlap. Further, the effect of aggregate randomness

488 on crack width development of concrete was investigated. The developed model was partially

489 verified by comparing the results with those from experiments. A parametric study was

490 carried out to examine the effects of some underlying parameters, e.g., shear fracture energy,

491 ITZ strength, cover thickness and uniform corrosion, on the crack pattern and the

492 development of crack width. Moreover, the models based on uniform corrosion of

493 reinforcement overestimated the time to surface cracking and underestimated the crack width,

494 especially for thicker cover. It can be concluded that the numerical model presented in the

495 paper can be used to simulate the meso-scale fracture of concrete structures which is

496 subjected to non-uniform corrosion of reinforcement.

497

498

\section{ACKNOWLEDGEMENTS}

499

Financial support from European Commission via the Marie Sklodowska-Curie H2020 RISE

500

scheme under 645696 and National Key R\&D Plan of China (Grant No: 2016YFC0600803)

501 are gratefully acknowledged. Part computational results were obtained by using ARCHIE-

502 WeSt High Performance Computer. The first author would also like to thank China

503 Scholarship Council for supporting his PhD research at the University of Strathclyde, UK.

\section{REFERENCES}

506 [1] Li CQ, Yang ST. Prediction of concrete crack width under combined reinforcement

507 corrosion and applied load. J Eng Mech. 2011;137:722-31.

508 [2] Li CQ, Melchers RE, Zheng JJ. Analytical model for corrosion-induced crack width in

509 reinforced concrete structures. ACI Structural Journal. 2006;103:479-87.

510 [3] Liu Y, Weyers RE. Modelling the time-to-corrosion cracking in chloride contaminated

511 reinforced concrete structures. ACI Mater J. 1998;95:675-81. 
512 [4] Bhargava K, Ghosh AK, Mori Y, Ramanujam S. Model for cover cracking due to rebar

513 corrosion in RC structures. Eng Struct. 2006;28:1093-109.

514 [5] Lu C, Jin W, Liu R. Reinforcement corrosion-induced cover cracking and its time prediction for reinforced concrete structures. Corros Sci. 2011;53:1337-47.

[6] El Maaddawy T, Soudki K. A model for prediction of time from corrosion initiation to corrosion cracking. Cem Concr Compos. 2007;29:168-75.

[7] Bazant ZP. Physical model for steel corrosion in concrete sea structures - theory. Journal of the Structural Division-ASCE. 1979;105:1137-53.

[8] Yang S, Li K, Li C-Q. Analytical model for non-uniform corrosion-induced concrete cracking. Mag Concrete Res. 2017:1-10.

[9] Li CQ. Life-cycle modelling of corrosion-affected concrete structures: Propagation. J Struct Eng-ASCE. 2003;129:753-61.

[10] Cao C, Cheung MMS, Chan BYB. Modelling of interaction between corrosion-induced concrete cover crack and steel corrosion rate. Corros Sci. 2013;69:97-109.

[11] Sanz B, Planas J, Sancho JM. An experimental and numerical study of the pattern of cracking of concrete due to steel reinforcement corrosion. Eng Fract Mech. 2013;114:26-41.

[12] Jang BS, Oh BH. Effects of non-uniform corrosion on the cracking and service life of reinforced concrete structures. Cem Concr Res. 2010;40:1441-50.

[13] Zhang J, Ling X, Guan Z. Finite element modeling of concrete cover crack propagation due to non-uniform corrosion of reinforcement. Constr Build Mater. 2017;132:487-99.

[14] Zhu X, Zi G. A 2D mechano-chemical model for the simulation of reinforcement corrosion and concrete damage. Constr Build Mater. 2017;137:330-44.

[15] Qiao D, Nakamura H, Yamamoto Y, Miura T. Crack patterns of concrete with a single rebar subjected to non-uniform and localized corrosion. Constr Build Mater. 2016;116:36677.

[16] Val; DV, Chernin; L, Stewart MG. Experimental and Numerical Investigation of Corrosion-Induced Cover Cracking in Reinforced Concrete Structures. J Struct Eng. 2009;135:10.

[17] Chernin L, Val DV. Prediction of corrosion-induced cover cracking in reinforced concrete structures. Constr Build Mater. 2011;25:1854-69.

[18] Zhang W, Ye Z, Gu X. Effects of stirrup corrosion on shear behaviour of reinforced concrete beams. Struct Infrastruct E. 2016;13:1081-92.

[19] Chen E, Leung CKY. Finite element modeling of concrete cover cracking due to nonuniform steel corrosion. Eng Fract Mech. 2015;134:61-78.

[20] Xi X, Yang S. Time to surface cracking and crack width of reinforced concrete structures under corrosion of multiple rebars. Constr Build Mater. 2017;155:114-25.

[21] Šavija B, Luković M, Pacheco J, Schlangen E. Cracking of the concrete cover due to reinforcement corrosion: A two-dimensional lattice model study. Constr Build Mater. 2013;44:626-38.

[22] Chen A, Pan Z, Ma R. Mesoscopic simulation of steel rebar corrosion process in concrete and its damage to concrete cover. Struct Infrastruct E. 2016;13:478-93.

[23] Du X, Jin L, Zhang R. Modeling the cracking of cover concrete due to non-uniform corrosion of reinforcement. Corros Sci. 2014;89:189-202.

[24] Yang ST, Li KF, Li CQ. Numerical determination of concrete crack width for corrosionaffected concrete structures. Comput Struct. 2017.

[25] Farid Uddin AKM, Numata K, Shimasaki J, Shigeishi M, Ohtsu M. Mechanisms of crack propagation due to corrosion of reinforcement in concrete by AE-SiGMA and BEM. Constr Build Mater. 2004;18:181-8.

[26] Gálvez JC, Cendón DA, Planas J. Influence of shear parameters on mixed-mode fracture of concrete. Int J Fracture. 2002;118:163-89. 
[27] Lens LN, Bittencourt E, d'Avila VMR. Constitutive models for cohesive zones in mixed-mode fracture of plain concrete. Eng Fract Mech. 2009;76:2281-97. [28] Camanho PP, Davila CG, Moura MFd. Numerical Simulation of Mixed-Mode Progressive Delamination in Composite Materials. J Compos Mater. 2002;34:1415-38. considering spatially varying random fracture properties. Comput Method Appl M. 2008;197:4027-39.

[30] Caré S, Nguyen QT, L'Hostis V, Berthaud Y. Mechanical properties of the rust layer induced by impressed current method in reinforced mortar. Cem Concr Res. 2008;38:107991.

[31] Yang ST, Li KF, Li CQ. Non-uniform corrosion-induced reinforced concrete cracking: an anlytical approach. In: J. Kruis YT, B.H.V. Topping, editor. 15th International Conference on Civil, Structural and Environmental Engineering Computing. Prague, Czech Republic: Civil-Comp Press; 2015.

[32] Yuan Y, Ji Y. Modeling corroded section configuration of steel bar in concrete structure. Constr Build Mater. 2009;23:2461-6.

[33] Neville AM. Properties of concrete. Fourth ed. London: Pearson Education Limited; 2006.

[34] Hillerborg A, Modeer M, Petersson PE. Analysis of crack formation and crack growth in concrete by means of fracture mechanics and finite elements. Cem Concr Res. 1976;6:77381.

[35] Kurumatani M, Terada K, Kato J, Kyoya T, Kashiyama K. An isotropic damage model based on fracture mechanics for concrete. Eng Fract Mech. 2016;155:49-66.

[36] Tabiei A, Zhang W. Cohesive element approach for dynamic crack propagation: Artificial compliance and mesh dependency. Eng Fract Mech. 2017;180:23-42.

[37] Kenane M, Benzeggagh ML. Mixed-mode delamination fracture toughness of unidirectional glass/epoxy composites under fatigue loading. Compos Sci Technol. 1997;57:597-605.

[38] Ren W, Yang Z, Sharma R, Zhang C, Withers PJ. Two-dimensional X-ray CT image based meso-scale fracture modelling of concrete. Eng Fract Mech. 2015;133:24-39.

[39] Wang X, Zhang M, Jivkov AP. Computational technology for analysis of 3D mesostructure effects on damage and failure of concrete. Int J Solids Struct. 2016;80:310-33.

[40] Trawiński W, Bobiński J, Tejchman J. Two-dimensional simulations of concrete fracture at aggregate level with cohesive elements based on X-ray $\mu \mathrm{CT}$ images. Eng Fract Mech. 2016;168:204-26.

[41] Xi X, Yang S, Li C-Q. A non-uniform corrosion model and meso-scale fracture modelling of concrete. Cem Concr Res. 2018;108:87-102.

[42] Dong W, Wu Z, Zhou X, Wang N, Kastiukas G. An experimental study on crack propagation at rock-concrete interface using digital image correlation technique. Eng Fract Mech. 2017;171:50-63.

[43] Tregger N, Corr D, Graham-Brady L, Shah S. Modeling the effect of mesoscale randomness on concrete fracture. Probabilist Eng Mech. 2006;21:217-25.

[44] Rao GA, Raghu Prasad BK. Influence of type of aggregate and surface roughness on the interface fracture properties. Mater Struct. 2004;37:328-34.

[45] Corr D, Accardi M, Graham-Brady L, Shah S. Digital image correlation analysis of interfacial debonding properties and fracture behavior in concrete. Eng Fract Mech. 2007;74:109-21.

[46] Hong L, Gu X, Lin F. Influence of aggregate surface roughness on mechanical properties of interface and concrete. Constr Build Mater. 2014;65:338-49. 
611 [47] Caré S, Nguyen QT, Beddiar K, Berthaud Y. Times to cracking in reinforced mortar 612 beams subjected to accelerated corrosion tests. Mater Struct. 2009;43:107-24.

613 [48] Andrade C, Molina FJ, Alonso C. Cover cracking as a function of rebar corrosion: Part 614 1-experiment test. Mater Struct. 1993;26:453-4.

615 
616 LIST OF TABLES

617 1. Three-segment gradation of aggregate size distribution [33]

618 2. Values for geometric and mechanical parameters for different phases

619 3. Values used for comparison and validation

620 


\begin{tabular}{cc}
\hline Aggregate size (mm) & Fraction (\%) \\
$2.40-4.76$ & $20.2 \%$ \\
$4.76-9.52$ & $39.9 \%$ \\
$9.52-19.05$ & $39.9 \%$ \\
\hline
\end{tabular}

622

623 
Table 2 Values for geometric and mechanical parameters for different phases

\begin{tabular}{ccc}
\hline Description & Symbol & Values \\
Cover thickness & $C$ & $40 \mathrm{~mm}$ \\
Diameter of steel bars & $D$ & $16 \mathrm{~mm}$ \\
Young's modulus of aggregate & $E_{\text {Agg }}$ & $70 \mathrm{GPa}[38]$ \\
Young's modulus of mortar & $E_{\text {Mor }}$ & $25 \mathrm{GPa}[38]$ \\
Poisson's ratio of aggregate & $v_{\text {Agg }}$ & $0.2[38]$ \\
Poisson's ratio of mortar & $v_{M o r}$ & $0.2[38]$ \\
Tensile strength of mortar & $\sigma_{n, M o r}$ & $2.6 \mathrm{MPa}[43,44]$ \\
Tensile strength of ITZ & $\sigma_{n, I T Z}$ & $1.3 \mathrm{MPa}[43,44]$ \\
Shear strength of mortar & $\sigma_{s, M o r}$ & $2.6 \mathrm{MPa}[43,44]$ \\
Shear strength of ITZ & $\sigma_{s, I T Z}$ & $1.3 \mathrm{MPa}[43,44]$ \\
Mode I fracture energy of mortar & $G_{I, M o r}$ & $40 \mathrm{~N} / \mathrm{m}[43,44]$ \\
Mode I fracture energy of ITZ & $G_{I, I T Z}$ & $17 \mathrm{~N} / \mathrm{m}[43,44]$ \\
Mode II fracture energy of mortar & $G_{I I, M o r}$ & $80 \mathrm{~N} / \mathrm{m}[43,44]$ \\
Mode II fracture energy of ITZ & $G_{I I, I T Z}$ & $34 \mathrm{~N} / \mathrm{m}[43,44]$ \\
\hline
\end{tabular}

625

626 
Table 3 Values used for comparison and validation

\begin{tabular}{cc} 
Description & Values \\
Cover thickness & $20 \mathrm{~mm} \mathrm{[48]}$ \\
Diameter of steel bars & $16 \mathrm{~mm} \mathrm{[48]}$ \\
Tensile strength of concrete & $3.5 \mathrm{MPa}[48]$ \\
Young's modulus of aggregate & $70 \mathrm{GPa}[38]$ \\
Young's modulus of mortar & $25 \mathrm{GPa}[38]$ \\
Poisson's ratio of aggregate & $0.2[38]$ \\
Poisson's ratio of mortar & $0.2[38]$ \\
Cohesive strength of mortar & $6 \mathrm{MPa}[38]$ \\
Cohesive strength of ITZ & $2 \mathrm{MPa}[38]$ \\
Fracture energy of mortar & $60 \mathrm{~N} / \mathrm{m} \mathrm{[38]}$ \\
Fracture energy of ITZ & $30 \mathrm{~N} / \mathrm{m} \mathrm{[38]}$ \\
\hline
\end{tabular}

628

629 
631 1. Non-uniform corrosion model

632 2. Insertion process of cohesive elements: (a) initial mesh; (b) inserted cohesive element

633 based on newly created nodes; and (c) mesh after insertion of cohesive elements

6343. Inserted cohesive elements in the FE mesh

635 4. Constitutive model for mixed-mode fracture

636 5. Typical mesh for the worked example

637 6. Crack propagation in concrete induced by non-uniform corrosion of reinforcement

638 7. Toughening mechanisms captured in the meso-scale model

639 8. Contributions of shear on the mixed-mode fracture

640 9. Crack patterns of 4 random meso-scale models

641 10. The crack width as a function of corrosion expansion displacement for 10 random meso-

$642 \quad$ scale models

643 11. Experimental verification of the crack width

644 12. Crack patterns under different fracture energies of Mode II

645 13. The crack width affected by fracture energies of Mode II

646 14. Crack patterns under different tensile and shear strengths of ITZ

647 15. The crack width developments under different tensile and shear strengths of ITZ

648 16. Crack patterns for different thicknesses of concrete cover

649 17. The crack width developments for different thicknesses of concrete cover

650 18. Crack patterns of concrete cover induced by uniform corrosion of reinforcement

651 19. The crack width developments with corrosion degree 


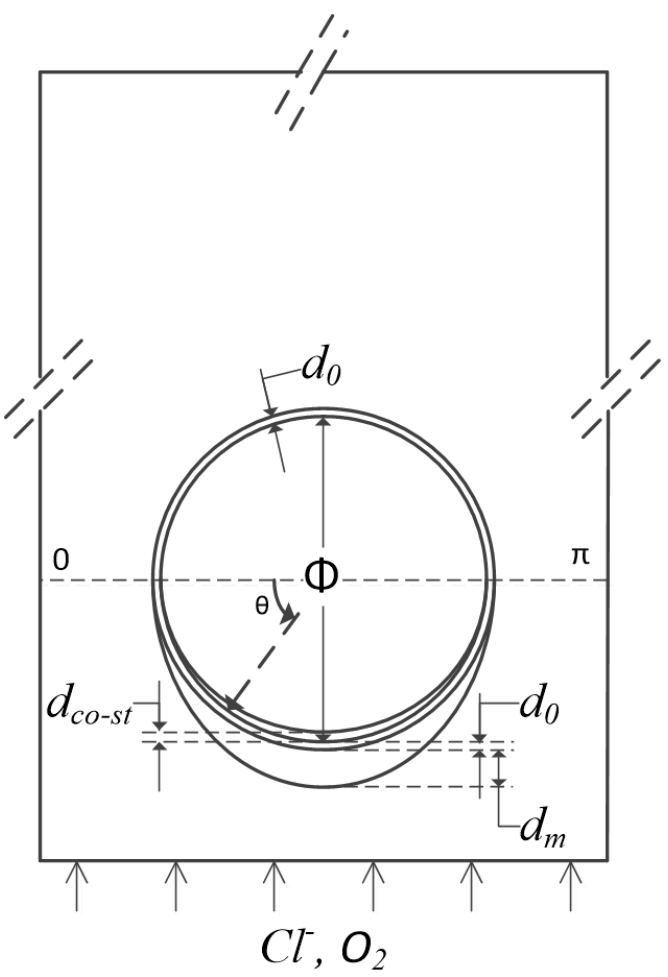




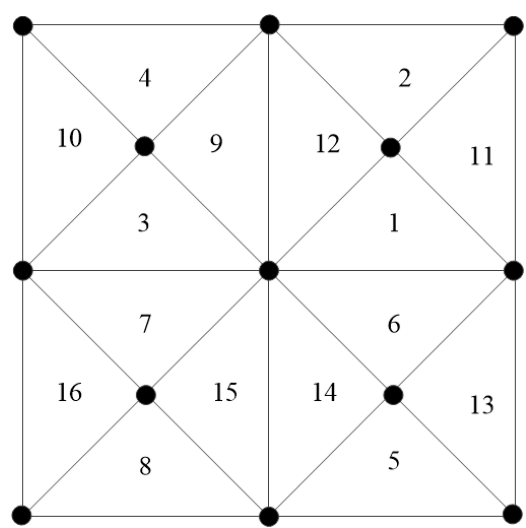

(a)

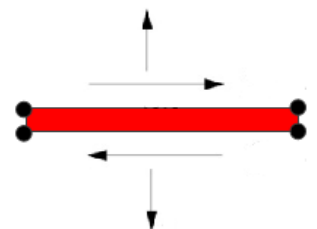

(b)

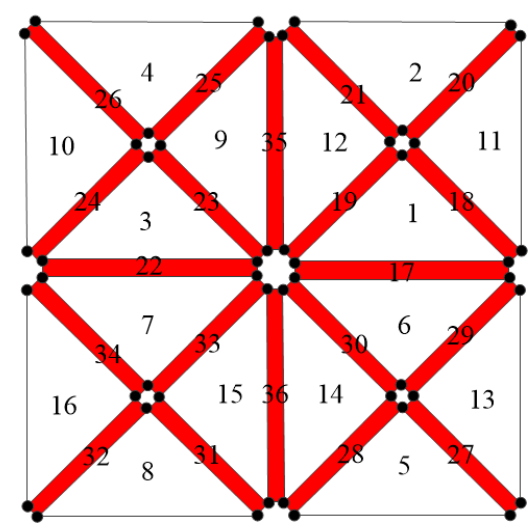

(c)
657

658

659

Figure 2 Insertion process of cohesive elements: (a) initial mesh; (b) inserted cohesive element based on newly created nodes; and (c) mesh after insertion of cohesive elements 660 

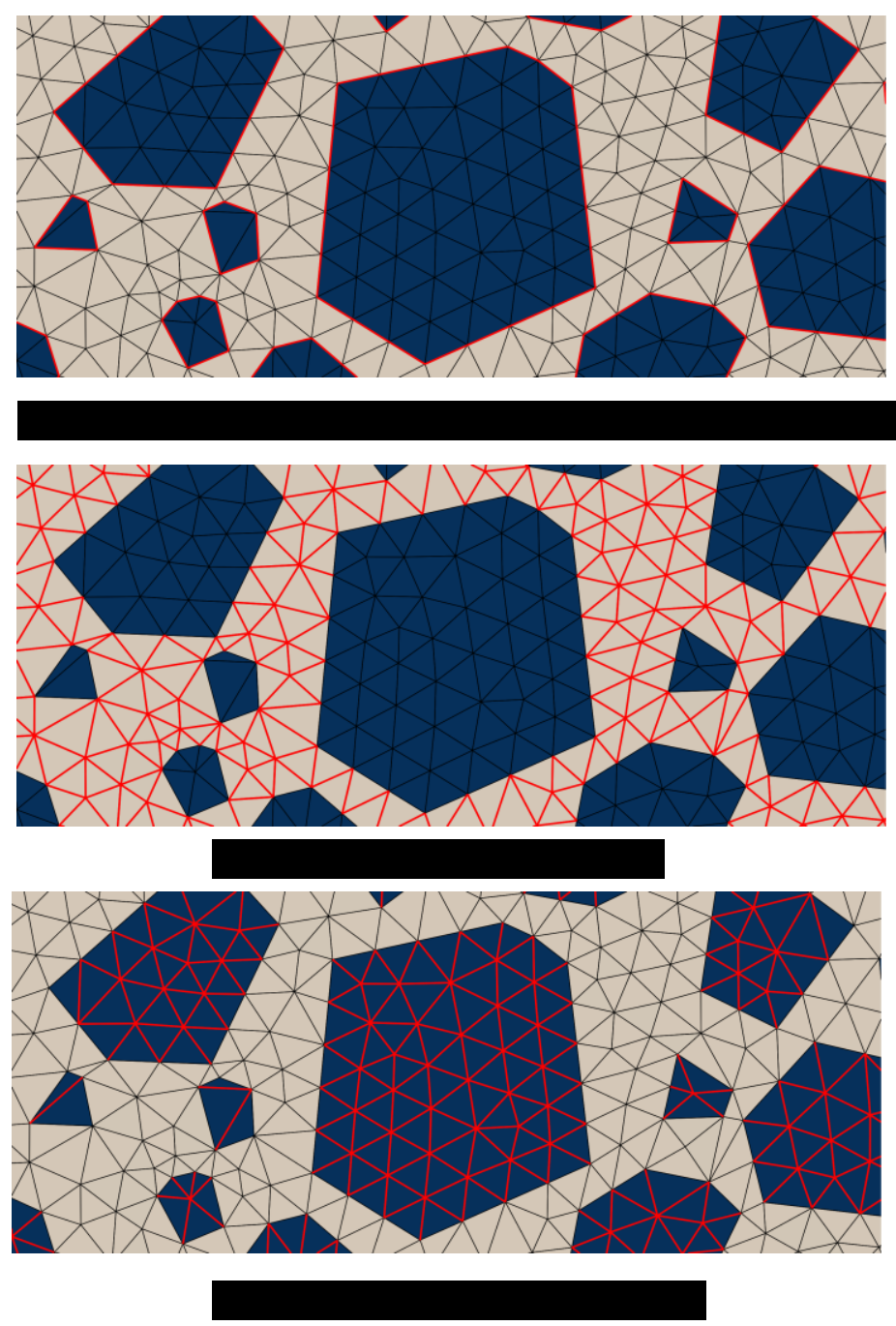

Figure 3 Inserted cohesive elements in the FE mesh 


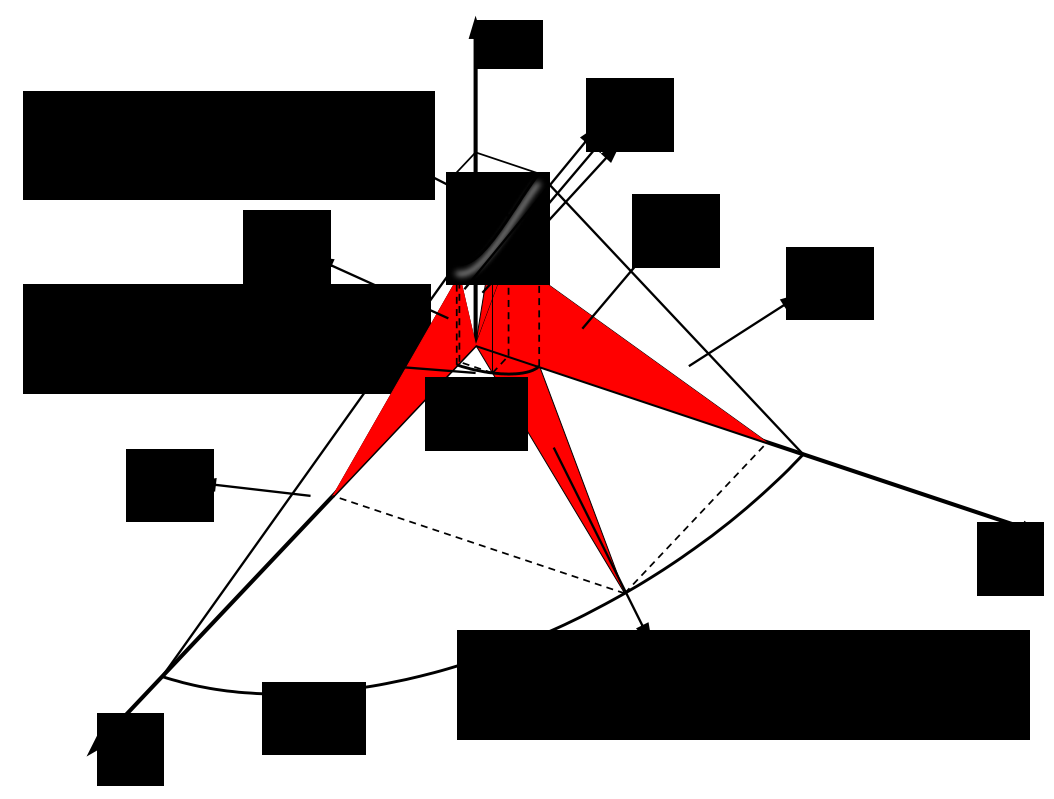

(a) Mixed-mode response model

667

668

669

670

671

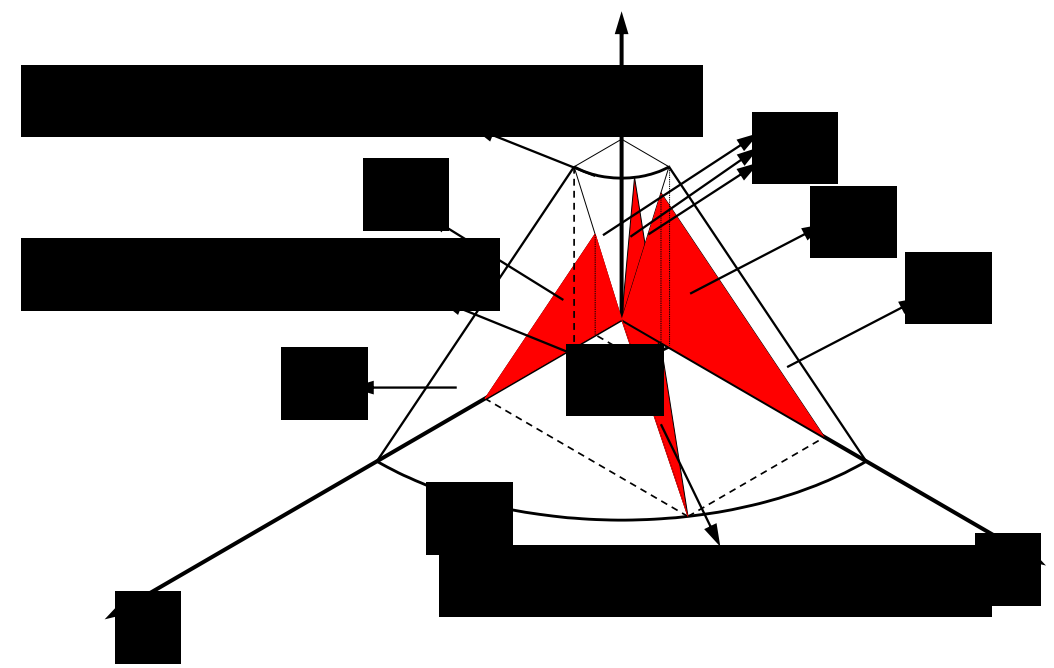

(b) A special case for $\sigma_{n}^{0}=\sigma_{s}^{0}$ and $G_{I}=G_{I I}$

Figure 4 Constitutive model for mixed-mode fracture 


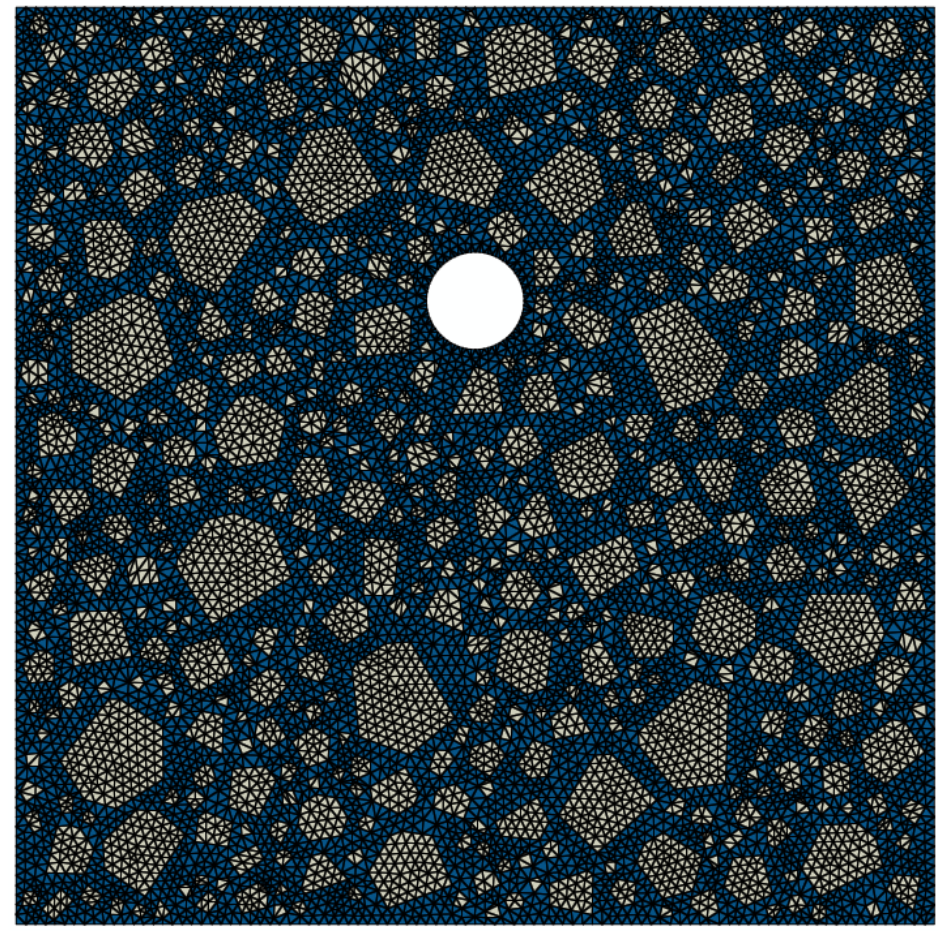

Figure 5 Typical Mesh for the worked example

674

675 
676

677

678

679

680

681

682

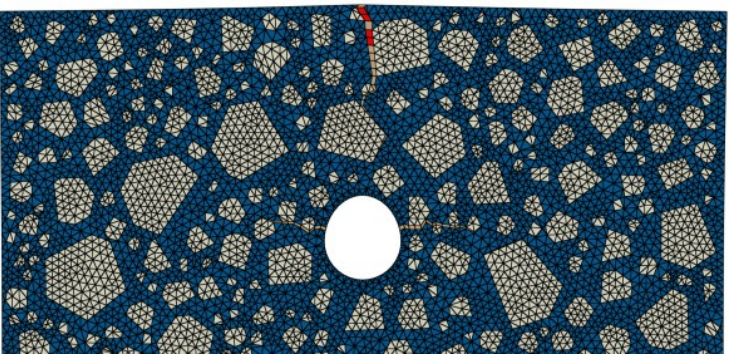

(a) $d_{m}=31.50 \mu \mathrm{m}$

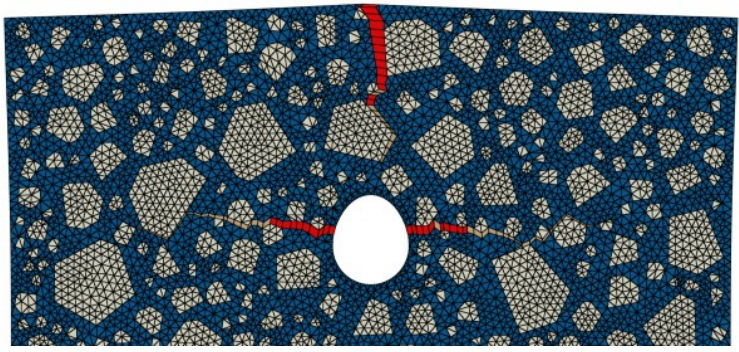

(c) $d_{m}=84.34 \mu \mathrm{m}$

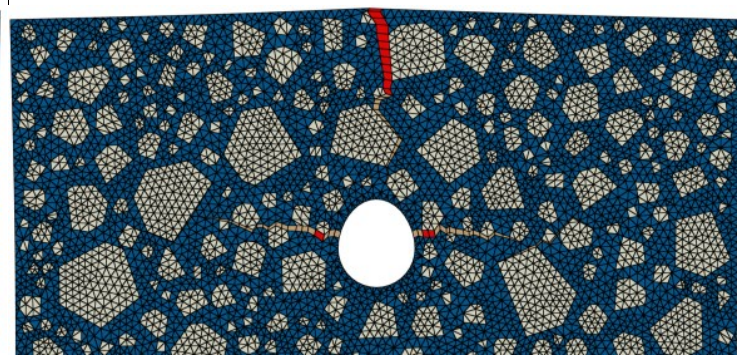

(b) $d_{m}=46.82 \mu \mathrm{m}$

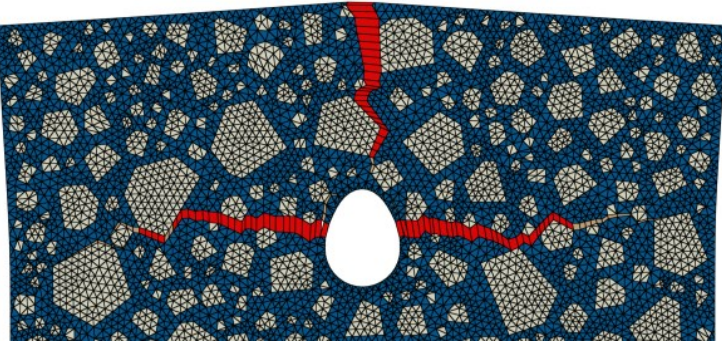

(d) $d_{m}=96.21 \mu \mathrm{m}$

Figure 6 Crack propagation in concrete induced by non-uniform corrosion of reinforcement

(Deformation scale 10$)$

683 
684

685

686

687

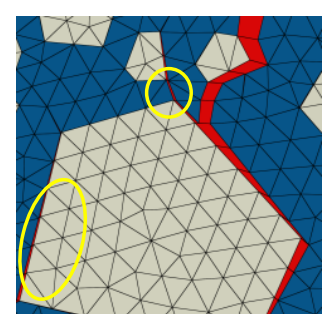

Microcrack shielding

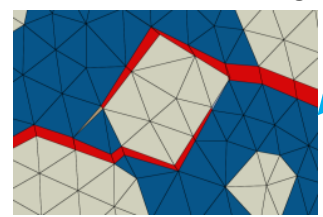

Aggregate bridging

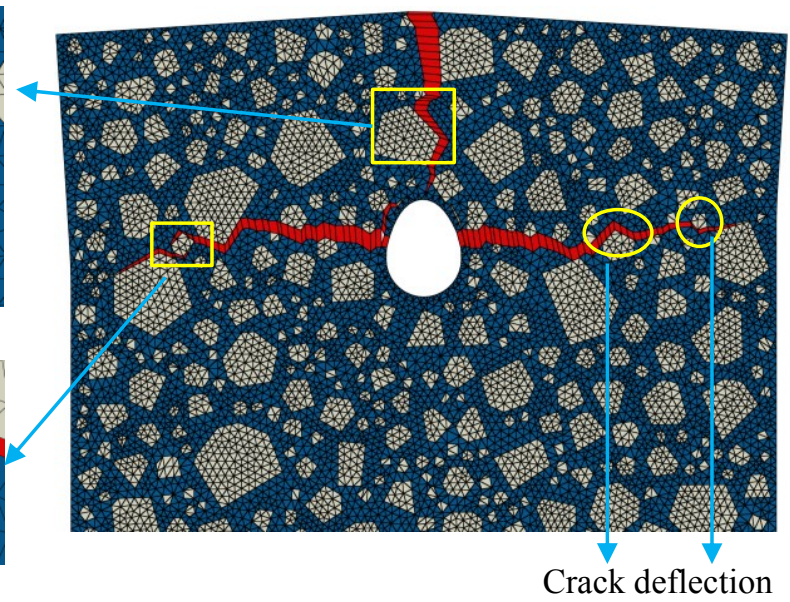

Figure 7 Toughening mechanisms captured in the meso-scale model 
688

689

690

691

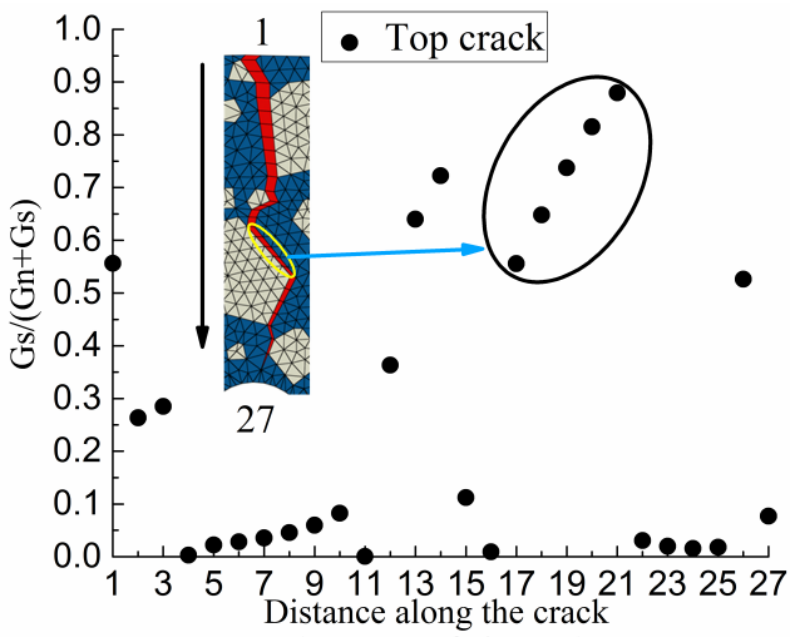

(In terms of element)

(a)

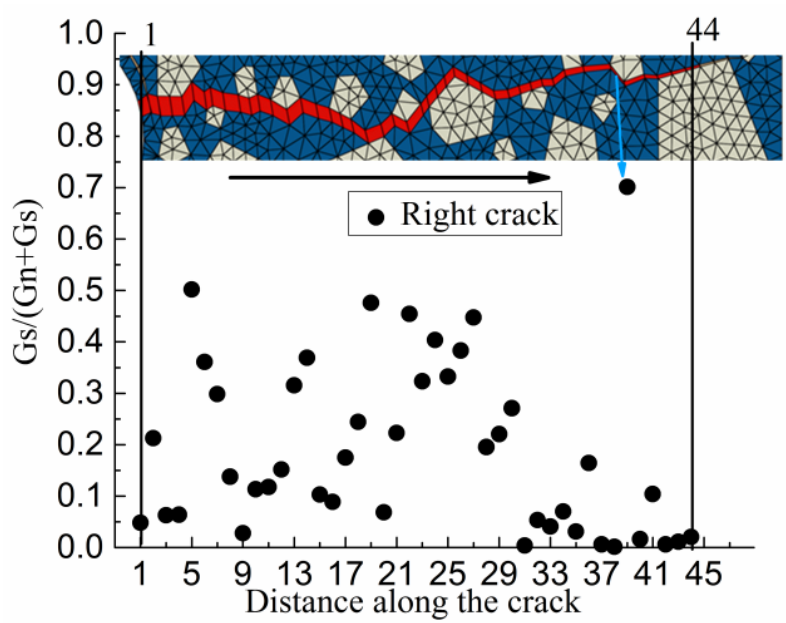

(In terms of element)

(b)

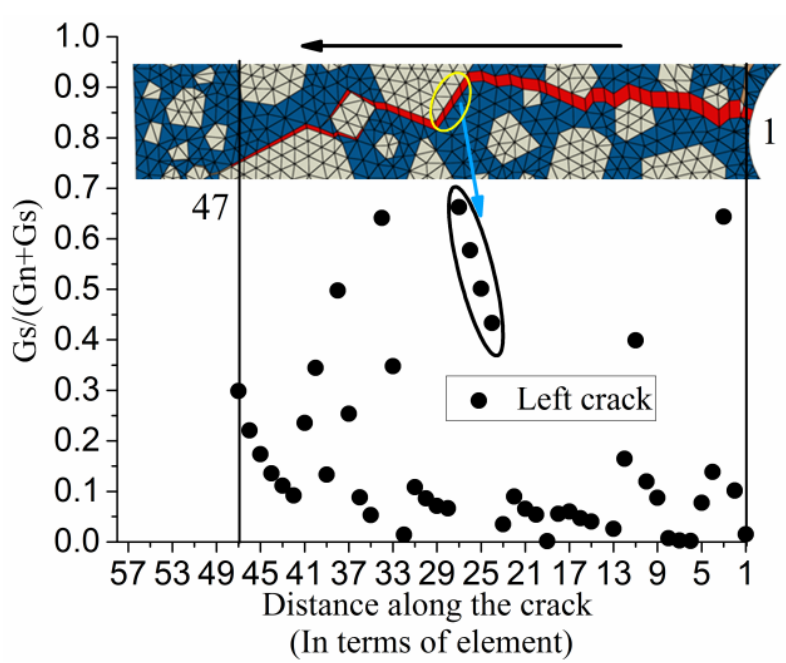

(c)

Figure 8 Contributions of shear on the mixed-mode fracture 
696

697

698

699

700

701

702

703

704

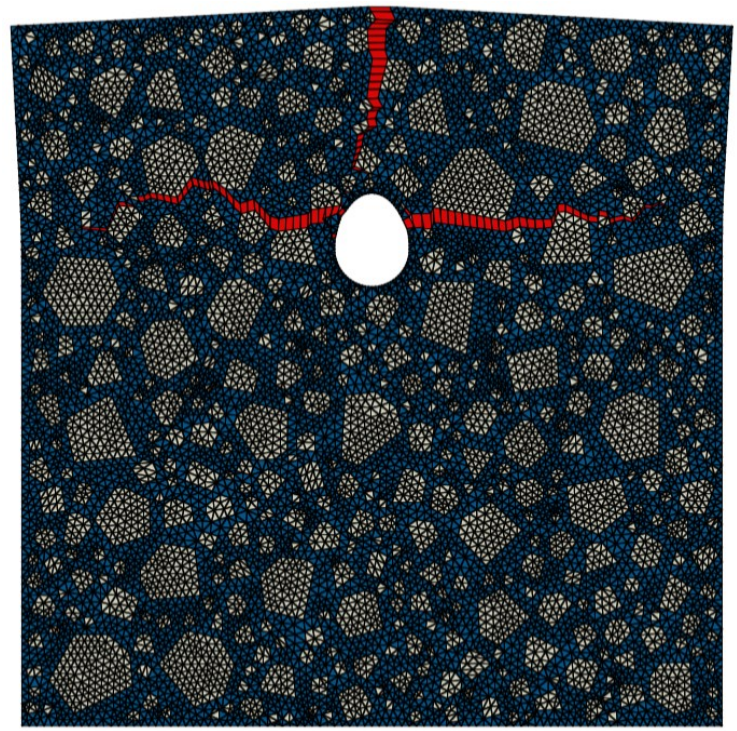

Random model 1

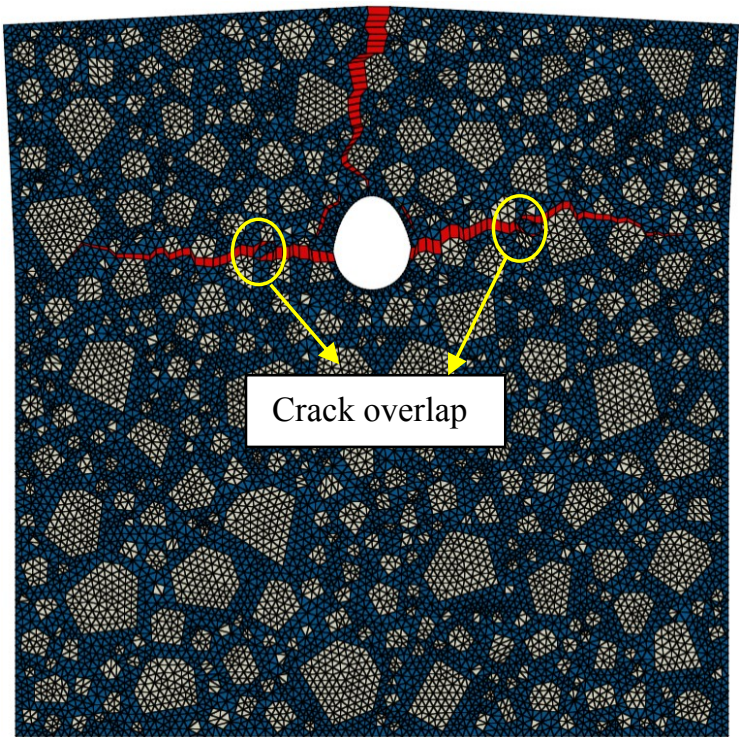

Random model 3

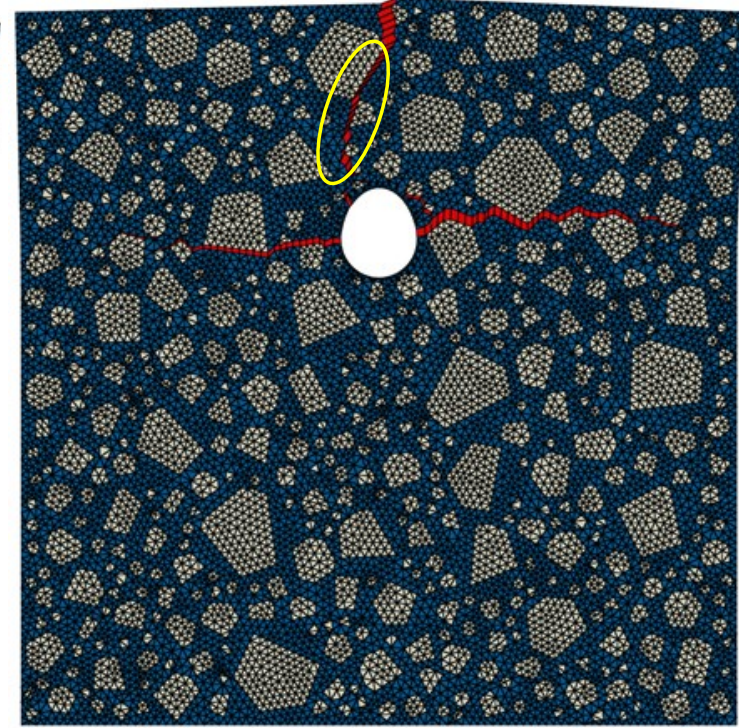

Random model 2

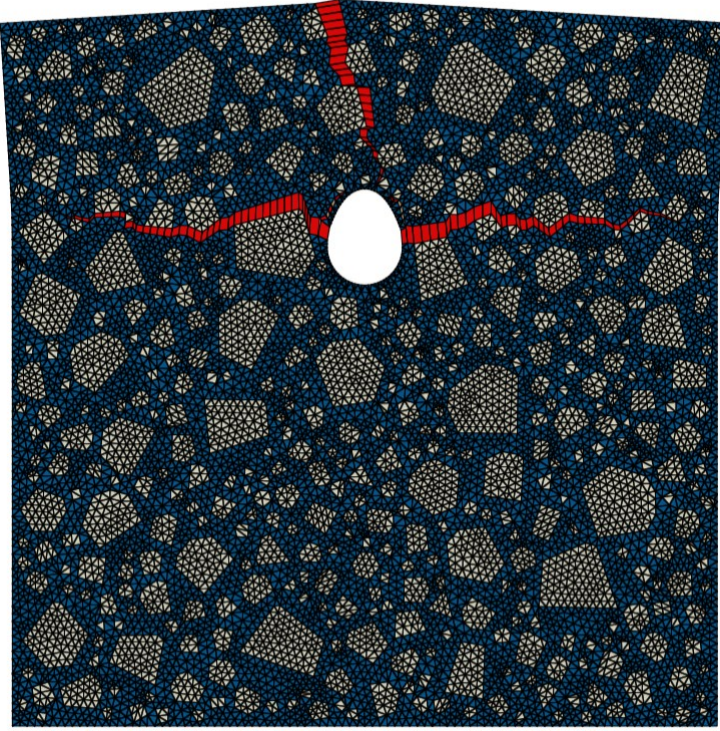

Random model 4

Figure 9 Crack patterns of 4 random meso-scale models 


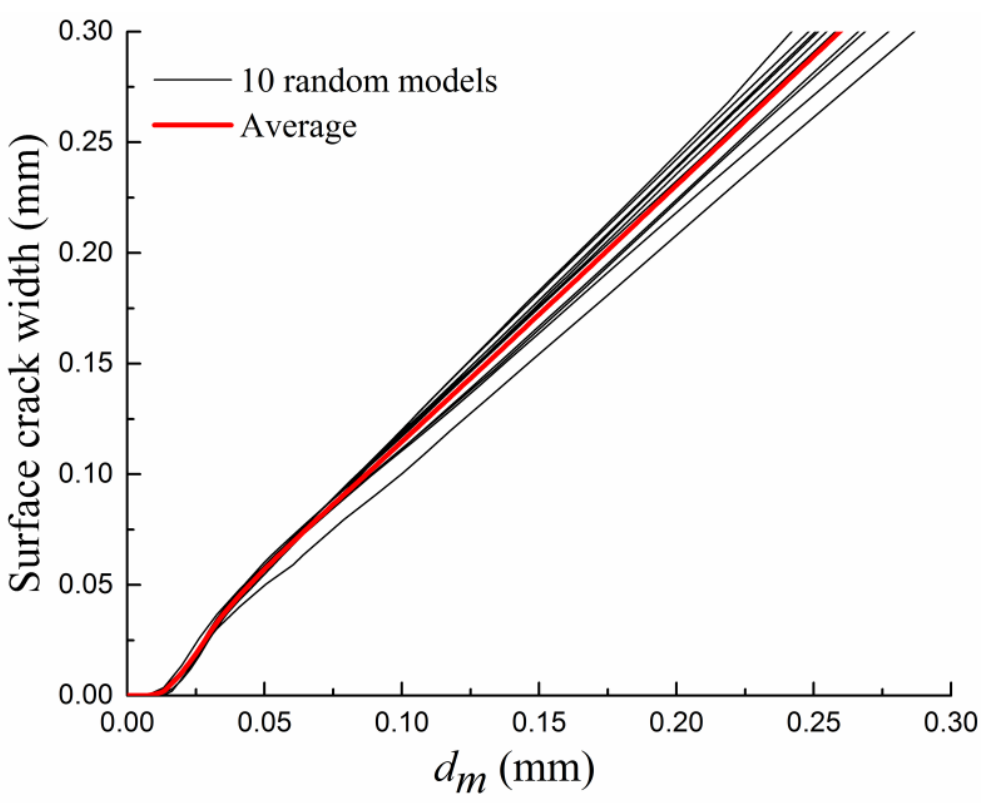

706 Figure 10 The crack width as a function of corrosion expansion displacement for 10 random 707 meso-scale models

708

709

710

711

712 


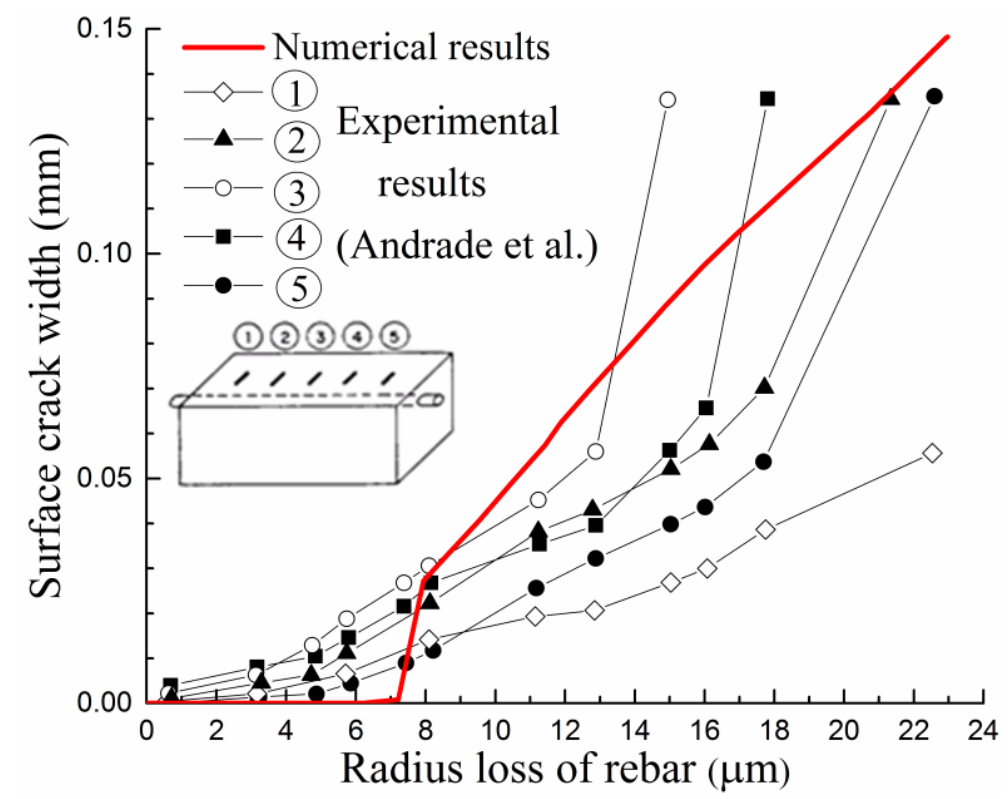


717

718

719

720

721

722

723

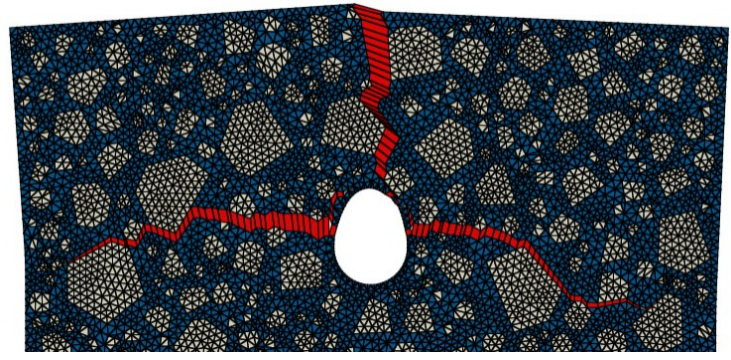

(a) $G_{I I}=G_{I}$

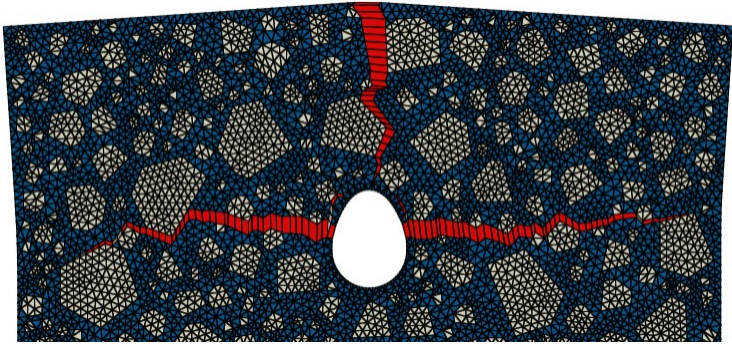

(c) $G_{I I}=10 G_{I}$

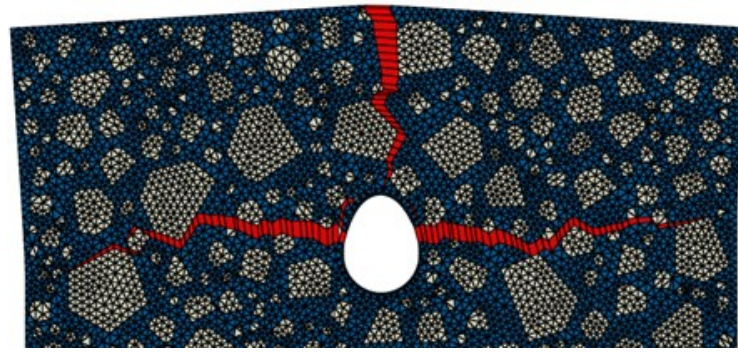

(b) $G_{I I}=2 G_{I}$

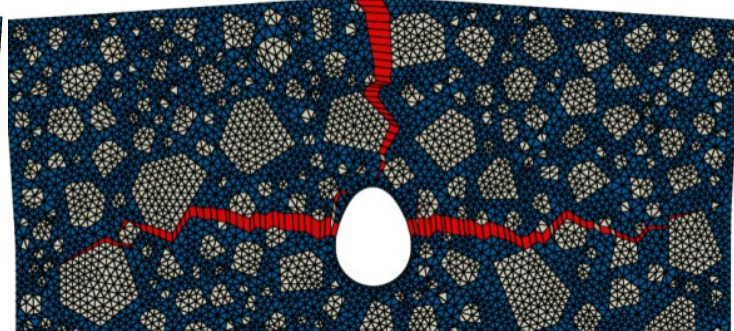

(d) $G_{I I}=20 G_{I}$

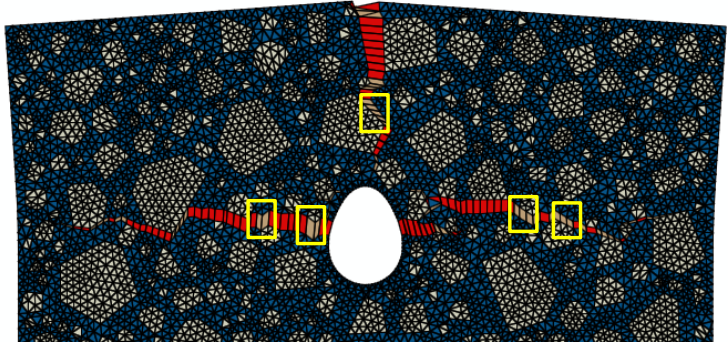

(e) $G_{I I}=100 G_{I}$

Figure 12 Crack patterns under different fracture energies of Mode II 


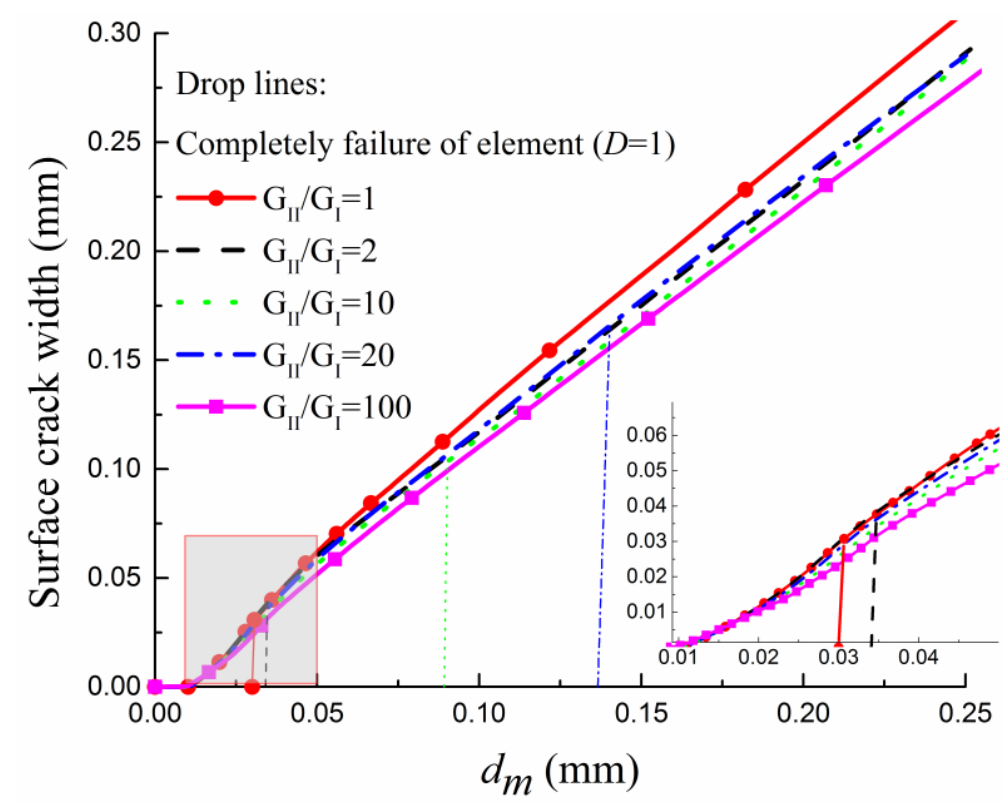


730

731

732

733

734

735

736

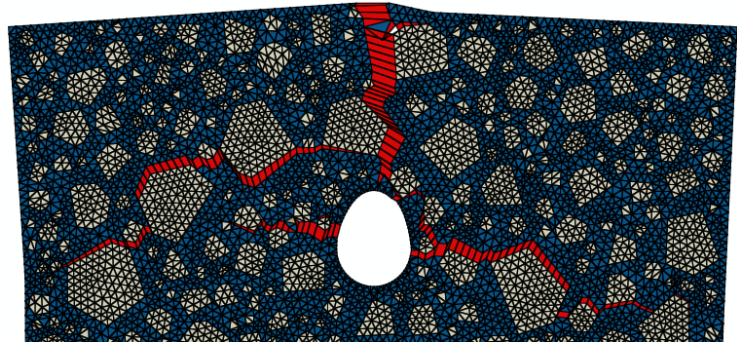

(a) $\sigma_{t, I T Z} / \sigma_{t, M o r}=1 / 8 ; \sigma_{s, I T Z} / \sigma_{s, M o r}=1 / 8$

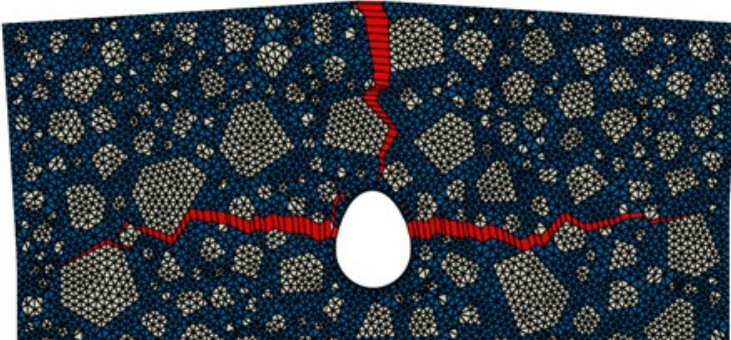

(c) $\sigma_{t, I T Z} / \sigma_{t, M o r}=1 / 2 ; \sigma_{s, I T Z} / \sigma_{s, M o r}=1 / 2$

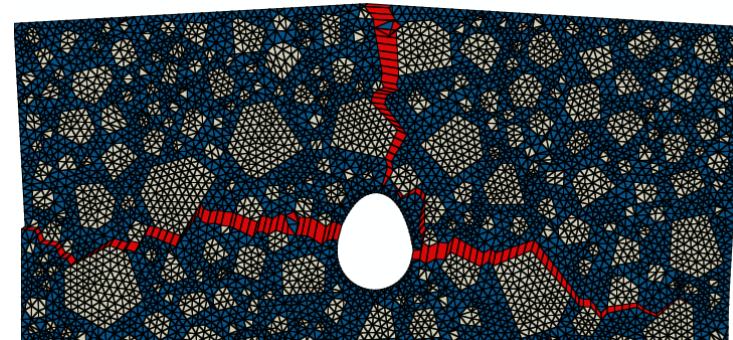

(b) $\sigma_{t, I T Z} / \sigma_{t, M o r}=1 / 4 ; \sigma_{s, I T Z} / \sigma_{s, M o r}=1 / 4$

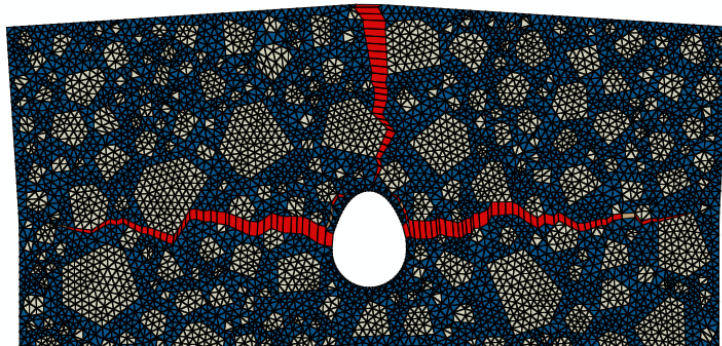

(d) $\sigma_{t, I T Z} / \sigma_{t, M o r}=3 / 4 ; \sigma_{s, I T Z} / \sigma_{s, M o r}=3 / 4$

Figure 14 Crack patterns under different tensile and shear strengths of ITZ 


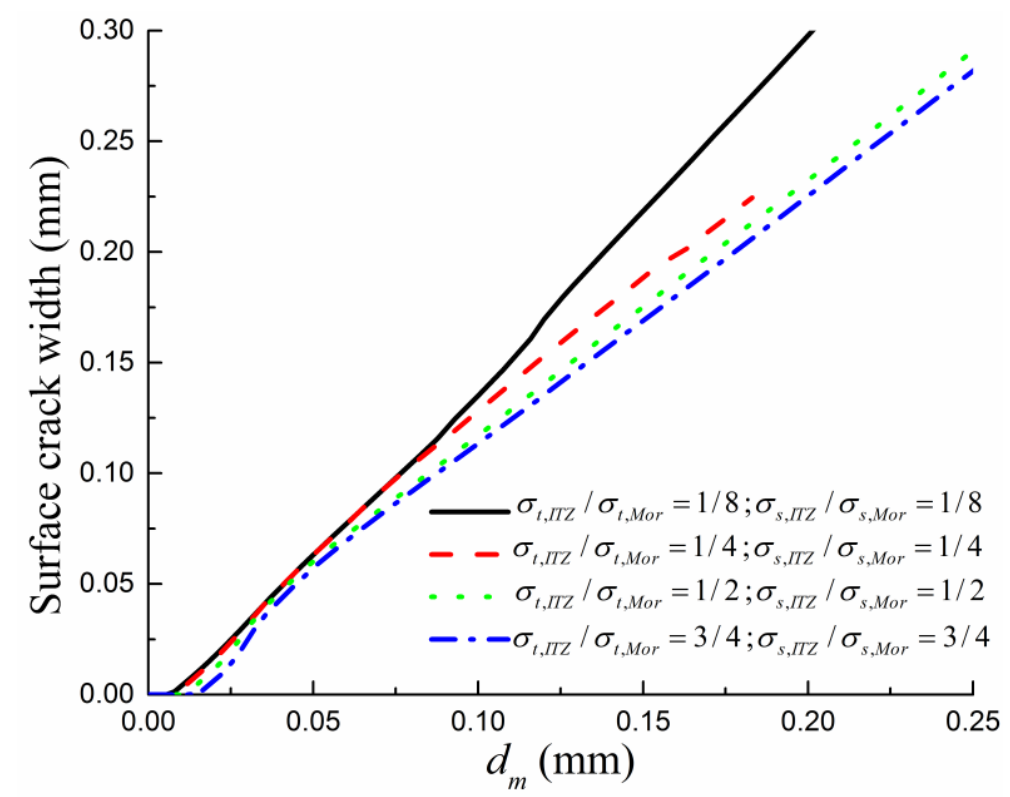

738 Figure 15 The crack width developments under different tensile and shear strengths of ITZ 


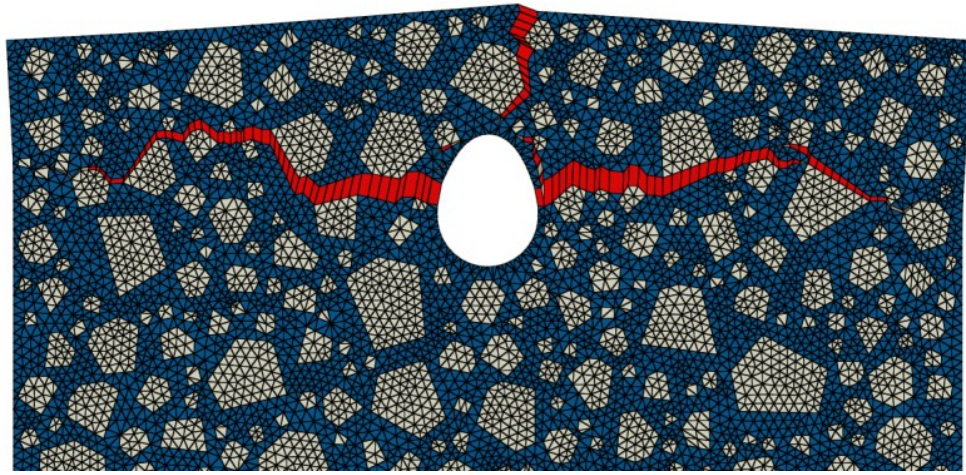

741

(a) $C=20 \mathrm{~mm}$

742

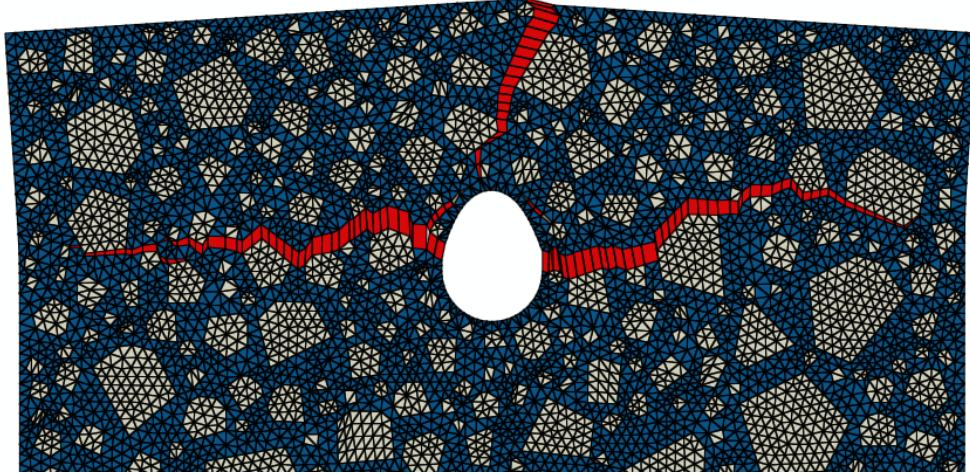

(b) $C=30 \mathrm{~mm}$

744

745

746

747

748

749

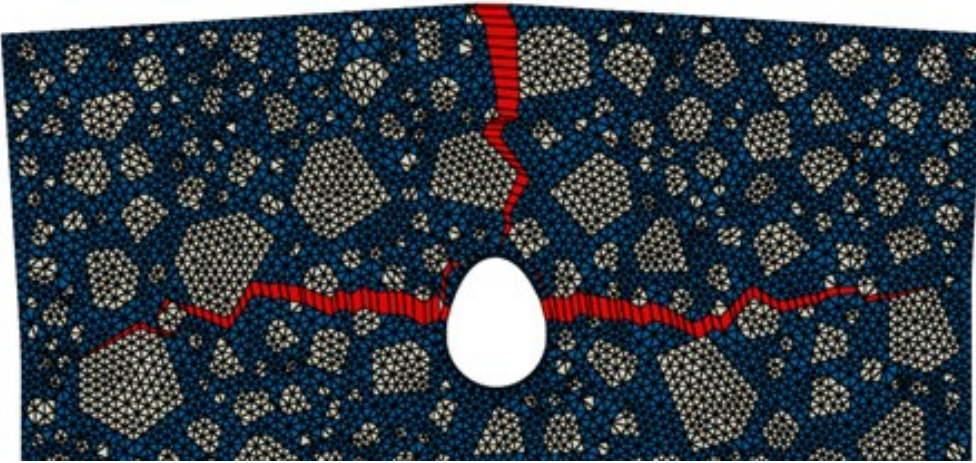

(c) $C=40 \mathrm{~mm}$

Figure 16 Crack patterns for different thicknesses of concrete cover 


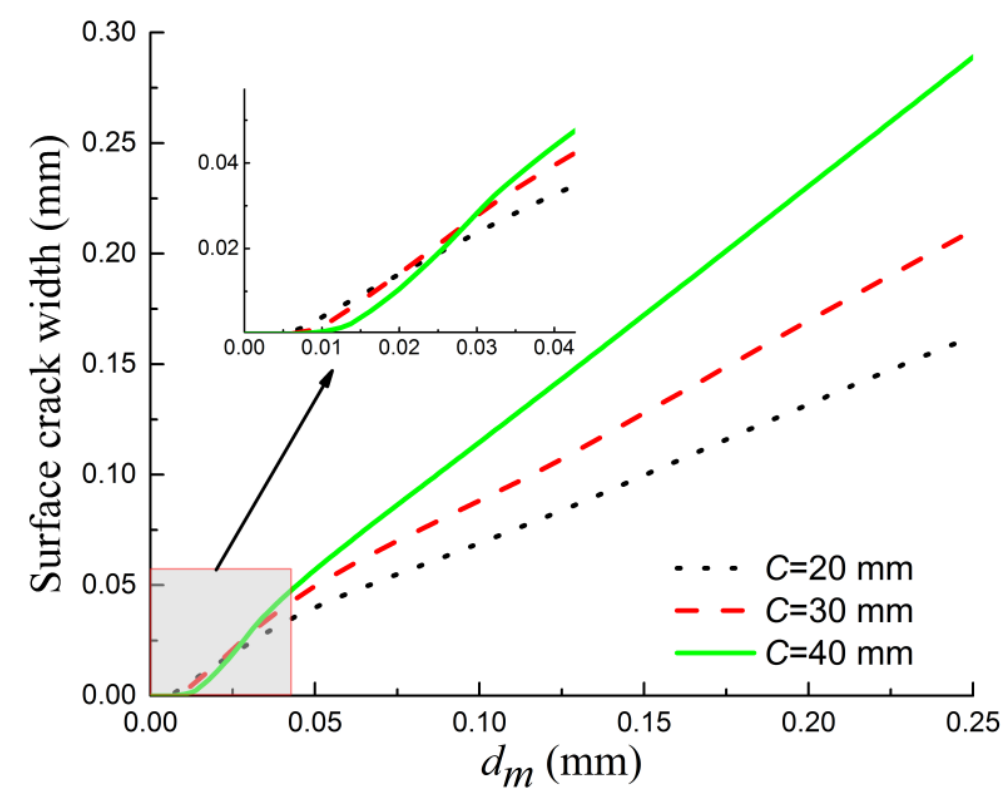

751 Figure 17 The crack width developments for different thicknesses of concrete cover 
754

755

756

757

758

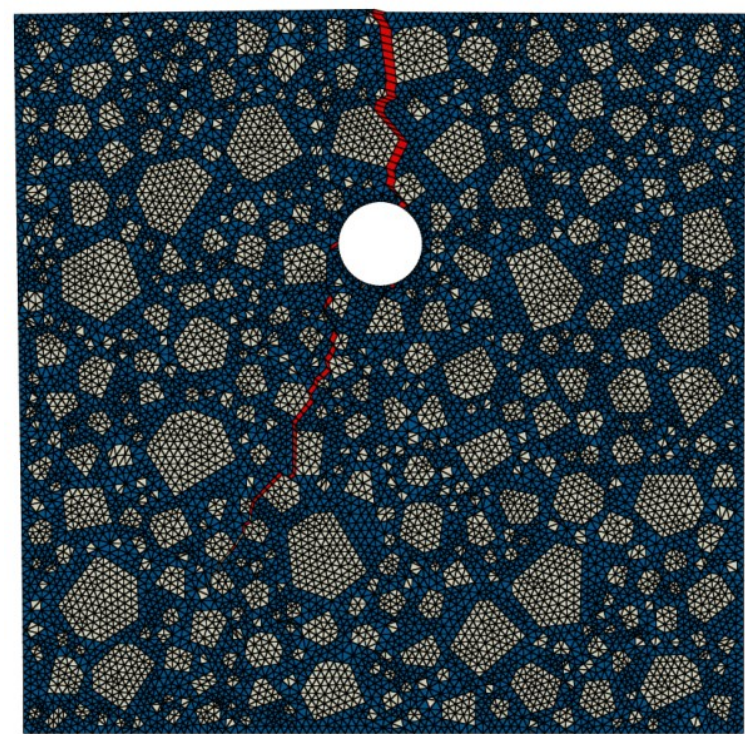

(b) $C=40 \mathrm{~mm} \&$ Uniform corrosion

(a) $C=20 \mathrm{~mm} \&$ Uniform corrosion

Figure 18 Crack patterns of concrete cover induced by uniform corrosion of reinforcement 


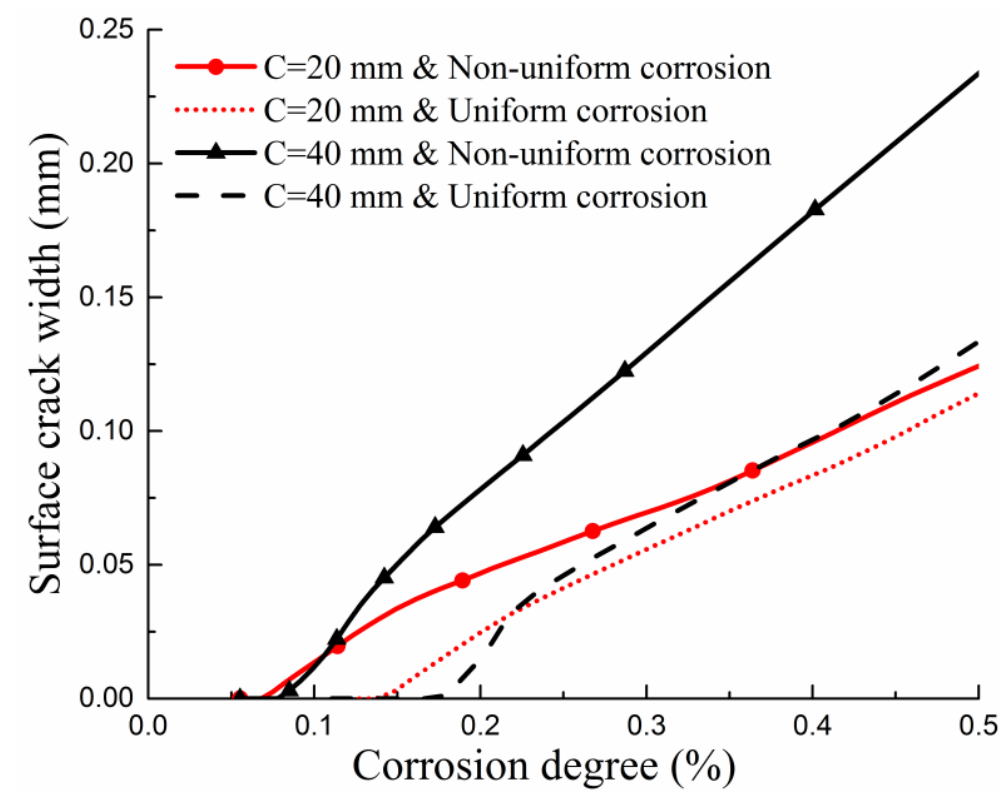

Figure 19 The crack width developments with corrosion degree 